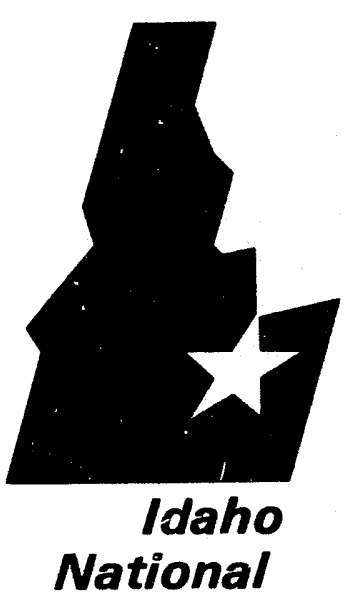

Engineering

Laboratory

Managed

by the U.S.

Department

of Energy
EGG-MS-9886

September 1991

INFORMAL REPORT

Nondestructive Evaluation of Advanced Ceramic Composite Materials
L. A. Lott

D. C. Kunerth

J. B. Walter

Research Sponsored by the U.S. Department of Energy Fossil Energy Advanced Research and Technology Development Materials Program

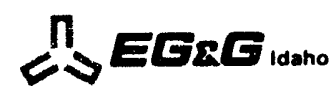

Work performed under DOE Contract No. DE-ACO7-761001570
Nov $2 \div 1991$ 
This report has been reproduced directly from the best available copy.

Available to DOE and DOE contractors from the Office of Sciemific and Technical Information, P.O. Box 62, Oak Ridge, TN 37831; prices available from (615) 576-8401, FTS 626-8401.

Available to the public from the National Technical Information Service, U.S. Depanment of Commerce, 5285 Port Royal Rd., Springfield, VA 22161.

Price: $\quad$ Printed Copy

$\mathrm{AO3}$ Microfiche A01

This document contains new concepts or the author(s) interpretation of new calculations and/or measurements; accordingly. EG\&G Idaho. Inc. is required by the United States Government to include the following disclaimer:

\section{DISCLAIMER}

This report was prepared as an account of work sponsored by an agency of the United States Government. Netther the United States Government nor any agency thereof. nor any of their employees. makes any warranty. express or implied. or assumes any legal liability or responsibility for the accuracy. completeness. or usefulness of any information, apparatus. product or process disciosed, or represents that its use would not infringe privately owned rignts. References herein to any specitic commercial product, process, or service by trade name. irademark. manutacturer. or otherwise. does not necessarily constitute or imply its endorsement, recommendation. or favoring by the United States Government or any agency thereot The views and opinions of authors expressed herein do not necessarily state or reflect those of the United States Government or any agency thereot. 


\title{
NONDESTRUCTIVE EVALUATION OF ADVANCED CERAMIC COMPOSITE MATERIALS
}

\author{
L. A. Lott \\ D. C. Kunerth \\ J. B. Walter
}

Published September 1991

Idaho National Engineering Laboratory

EG\&G Idaho, Inc.

Idaho Falls, Idaho 83415

Research sponsored by the

U.S. Department of Energy

Fossil Energy

Advanced Research and Technology

Development Materials Program

Prepared for the

U.S. Department of Energy

Field Office, Idaho

Under DOE Contract No. DE-AC07-76ID01570

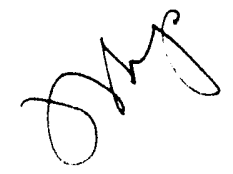




\begin{abstract}
Nondestructive evaluation techniques were developed to characterize performance degrading conditions in continuous fiber-reinforced silicon carbide/silicon carbide composites. Porosity, fibermatrix interface bond strength, and physical damage were among the conditions studied. The material studied is formed by chemical vapor infiltration (CVI) of the matrix material into a preform of woven reinforcing fibers. Acoustic, ultrasonic, and vibration response techniques were studied. Porosity was investigated because of its inherent presence in the CVI process and of the resultant degradation of material strength. Correlations between porosity and ultrasonic attenuation and velocity were clearly demonstrated. The ability of ultrasonic transmission scanning techniques to map variations in porosity in a single sample was also demonstrated. The fiber-matrix interface bond was studied because of its importance in determining the fracture toughness of the material. Correlations between interface bonding and acoustic and ultrasonic properties were observed. These results are presented along with those obtained from acoustic and vibration response measurements on material samples subjected to mechanical impact damage. This is the final report on research sponsored by the U.S. Department of Energy, Fossil Energy Advanced Research and Technology Development Materials Program.
\end{abstract}




\section{CONTENTS}

INTRODUCTION $\ldots \ldots \ldots \ldots \ldots \ldots \ldots \ldots \ldots \ldots \ldots \ldots \ldots \ldots \ldots \ldots$

EXPERIMENTAL TECHNIQUES $\ldots \ldots \ldots \ldots \ldots \ldots \ldots \ldots \ldots \ldots \ldots \ldots$

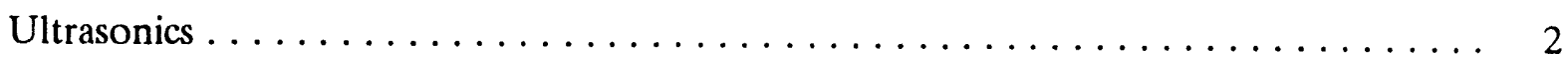

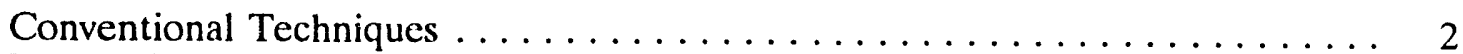

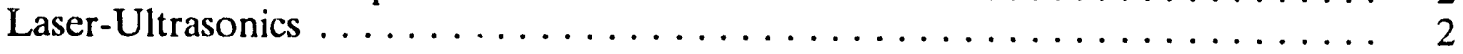

Acousto-Ultrasonics $\ldots \ldots \ldots \ldots \ldots \ldots \ldots \ldots \ldots \ldots \ldots \ldots \ldots \ldots$

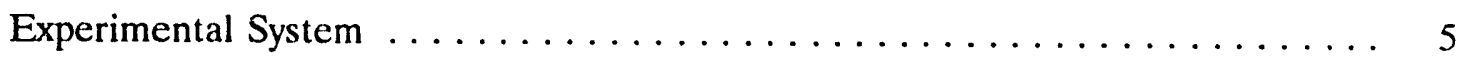

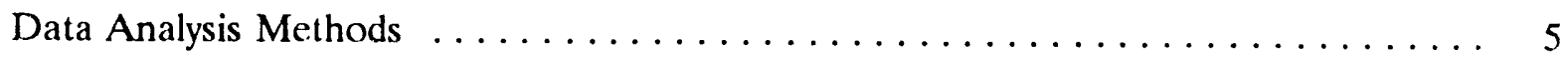

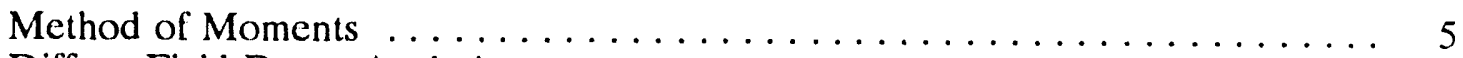

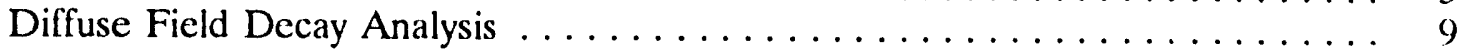

POROSITY AND VOIDS $\ldots \ldots \ldots \ldots \ldots \ldots \ldots \ldots \ldots \ldots \ldots \ldots \ldots \ldots$

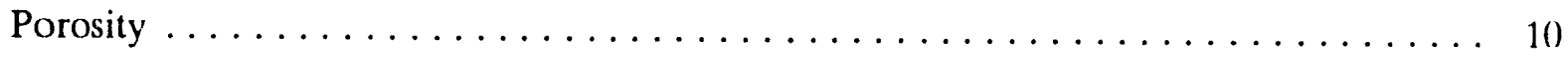

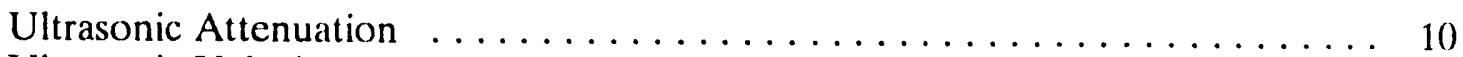

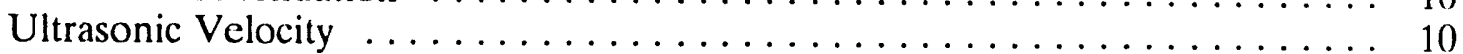

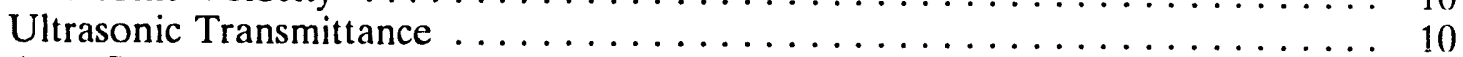

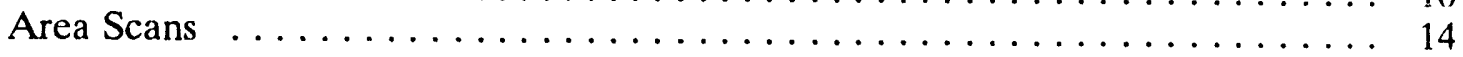

Void Detection $\ldots \ldots \ldots \ldots \ldots \ldots \ldots \ldots \ldots \ldots \ldots \ldots \ldots \ldots \ldots \ldots$

MECHANICAL DAMAGE CHARACTERIZATION $\ldots \ldots \ldots \ldots \ldots \ldots \ldots \ldots$

Acousto-Ultrasonic Measurements . . . . . . . . . . . . . . . . 21

Vibration Response Measurements $\ldots \ldots \ldots \ldots \ldots \ldots \ldots \ldots \ldots \ldots \ldots \ldots$

FIBER-MATRIX INTERFACE CHARACTERIZATION $\ldots \ldots \ldots \ldots \ldots \ldots \ldots$

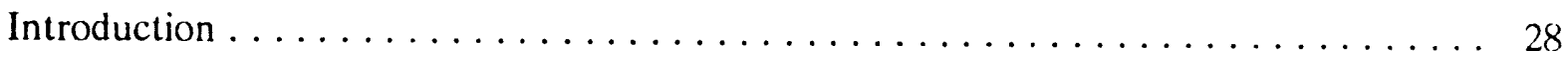

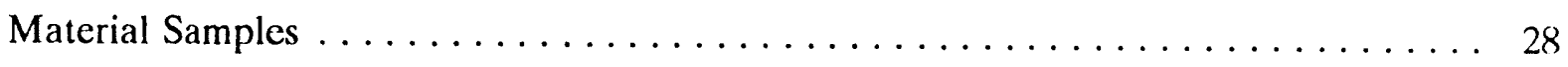

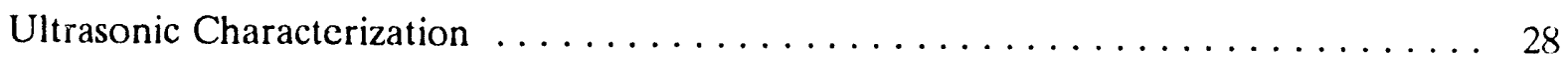

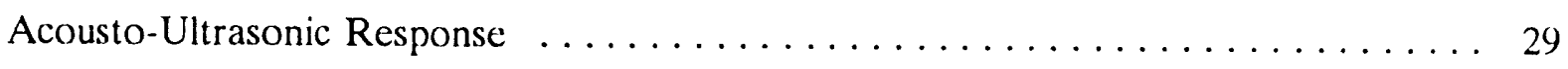

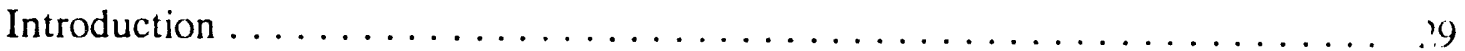

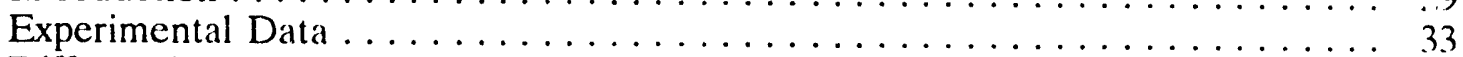

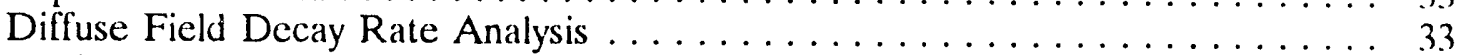

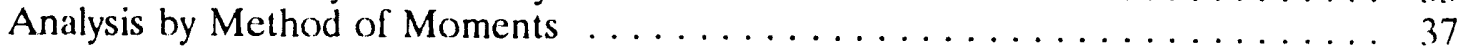

SUMMARY AND CONCLUSIONS $\ldots \ldots \ldots \ldots \ldots \ldots \ldots \ldots \ldots \ldots \ldots \ldots$ 4) 
REFERENCES . 


\section{NONDESTRUCTIVE EVALUATION OF ADVANCED CERAMIC COMPOSITE MATERIALS}

\section{INTRODUCTION}

This is the final report on research sponsored by the U.S. Department of Energy, Fossil Energy Advanced Research and Technology Development Materials Program, to develop nondestructive evaluation (NDE) techniques for characterizing advanced ceramic composite materials. These hightemperature structural materials are currently of great interest for fossil energy applications, because they exhibit significantly higher fracture toughness than monolithic ceramics. Because of the complexity of these materials, conventional NDE techniques are often incapable of characterizing the materials adequately. The objective of this study was to develop effective NDE techniques for detecting and characterizing those material conditions known to affect oughness and strengtit in continuous fiber-reinforced composites. Examples of known conditions include the degree of bonding between fiber and matrix, and physical damage such as fiber breakage and matrix cracking. Techniques investigated included ultrasonic velocity and attenuation, acousto-ultrasonic (AU) response, and internal dynamic mechanical damping.

The particular material considered in this study consists of continuous $\mathrm{SiC}$ fibers in a $\mathrm{SiC}$ matrix. The material is fabricated by first building up a preform from layers of Nicalon cloth (Nicalon is a trade name of the Nippon Carbon Co., Tokyo, Japan). A matrix of $\mathrm{SiC}$ is then added to the preform by a chemical vapor infiltration (CVI) process.

Research sponsored by the U.S. Department of Energy, Fossil Energy AR\&TD Materials Program, DOE/FE AA 151010 (), Work Breakdown Structure Element INEL-1(A) 


\title{
EXPERIMENTAL TECHNIQUES
}

\author{
Ultrasonics
}

\section{Conventional Techniques}

The ultrasonic measurements used in this study were accomplished with conventional throughtransmission techniques, in which separate sending and receiving transducers are placed on opposite sides of a plane parallel specimen. Ultrasonic velocity is determined by the known thickness of the specimen and the measured transit time of ultrasonic pulses through the specimen. Ultrasonic attenuation and transmission are determined by the relative amplitudes of the transmitted pulses.

\section{Laser-Ultrasonics}

Pulsed laser generation of ultrasound ${ }^{1,2}$ was found to be more effective than the use of conventional piezoelectric transducers for the more porous, highly attenuating ceramic matrix composite samples under study. Ultrasonic pulses were generated in SiC/SiC composite samples, by directing a pulsed Nd:YAG laser beam onto one surface. The ultrasonic pulse, which is gencrated at the sample surface either by the thermoelastic effect or by ablation of surface material, propagates through the sample and is detected on the opposite surface by either a piezoelectric transducer or a capacitive sensor as shown in Figure 1. The capacitive sensor, for which the sample surface itsclf serves as one plate of a capacitor, provides a direct measure of absolute displacement of the sample surface over a large bandwidth. Because of these attributes, it is an ideal sensor to study the characteristics of laser-generated ultrasound and propagation of the ultrasound through the material, although it is not generally a practical ultrasonic transducer because of its relatively low sensitivity and of the difficulty in maintaining a constant capacitor plate separation of anproximately $20 \mu \mathrm{m}$. To increase the sensitivity of the sensor, the sample surface next to the sensor was coated, by vacuum deposition, with an electrically conducting thin film of platinum metal.

The transmitted ultrasonic pulses were recorded for different incident laser pulse energies and sample surface conditions. These pulses included low energy laser pulses, in which ultrasound is generated by the thermoelastic effect and for which no ablation of the surface is produced, and higher laser energies, where ultrasound is generated either as the sample material itself or as a thin film of oil ablated from the surface.

Figure 2 shows typical low laser energy transmitted ultrasonic pulses generated by thermoelastic conversion in the $\mathrm{SiC} / \mathrm{SiC}$ composite material. These pulses ar similar to those produced by thermoelastic conversion in monolithic metal (steel) samples of comparable thicknesses $(3.3 \mathrm{~mm})$. The pulses are significantly different from ultrasonic pulses produced and detected with conventional piezoclectric transducers. This is because the signals generated and detected by piezoclectric transducers are strongly influenced by the resonant vibration modes of the transducer itself, whereas the capacitive sensor measures the absolute displacement of the sample surface as mentioned. By comparison with theoretical modeling of the laser generation process, the features of the pulse can be explained. The laser pulse is incident on the sample surface at the point in time labeled LP in Figure 2. The arrival of the longitudinal component of the pulse at the back surface of the sample is labeled $\mathrm{L}$. The point labeled $\mathrm{S}$ is the arrival of the shear wave component of the pulse. The propagation velocities of the wave components can be determined from the arrival times. The oscillations in the pulse following the first longitudinal and shear arrivals are produced by different vibration modes of the plate samples and by scattering of the ultrasonic wave by the porosity and reinforcing fibers in the material. There is potential information in these signals about the structure of the material. 


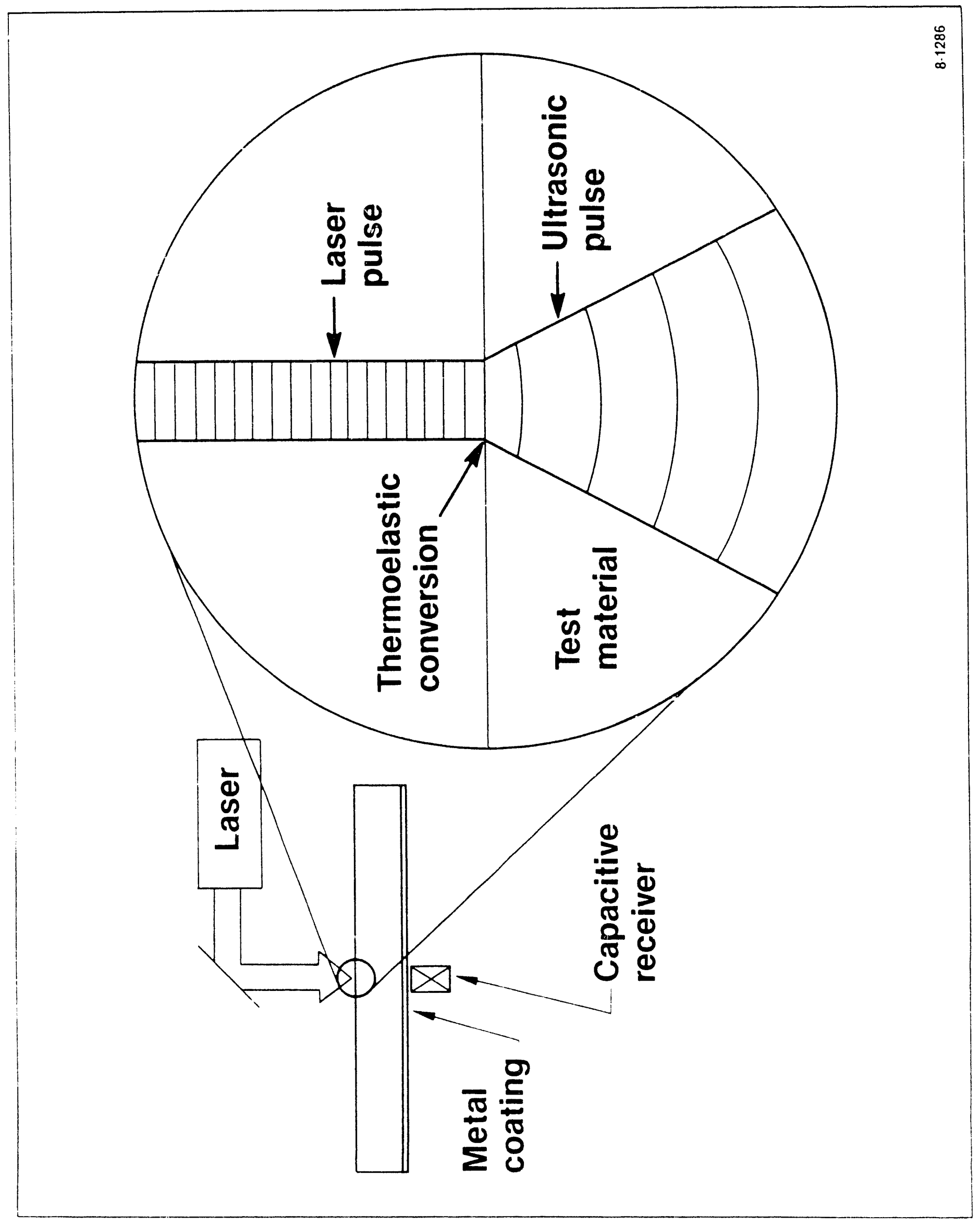

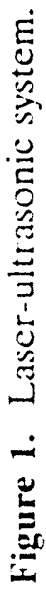




\section{Laser Generated Ultrasonic Pulse Shapes}

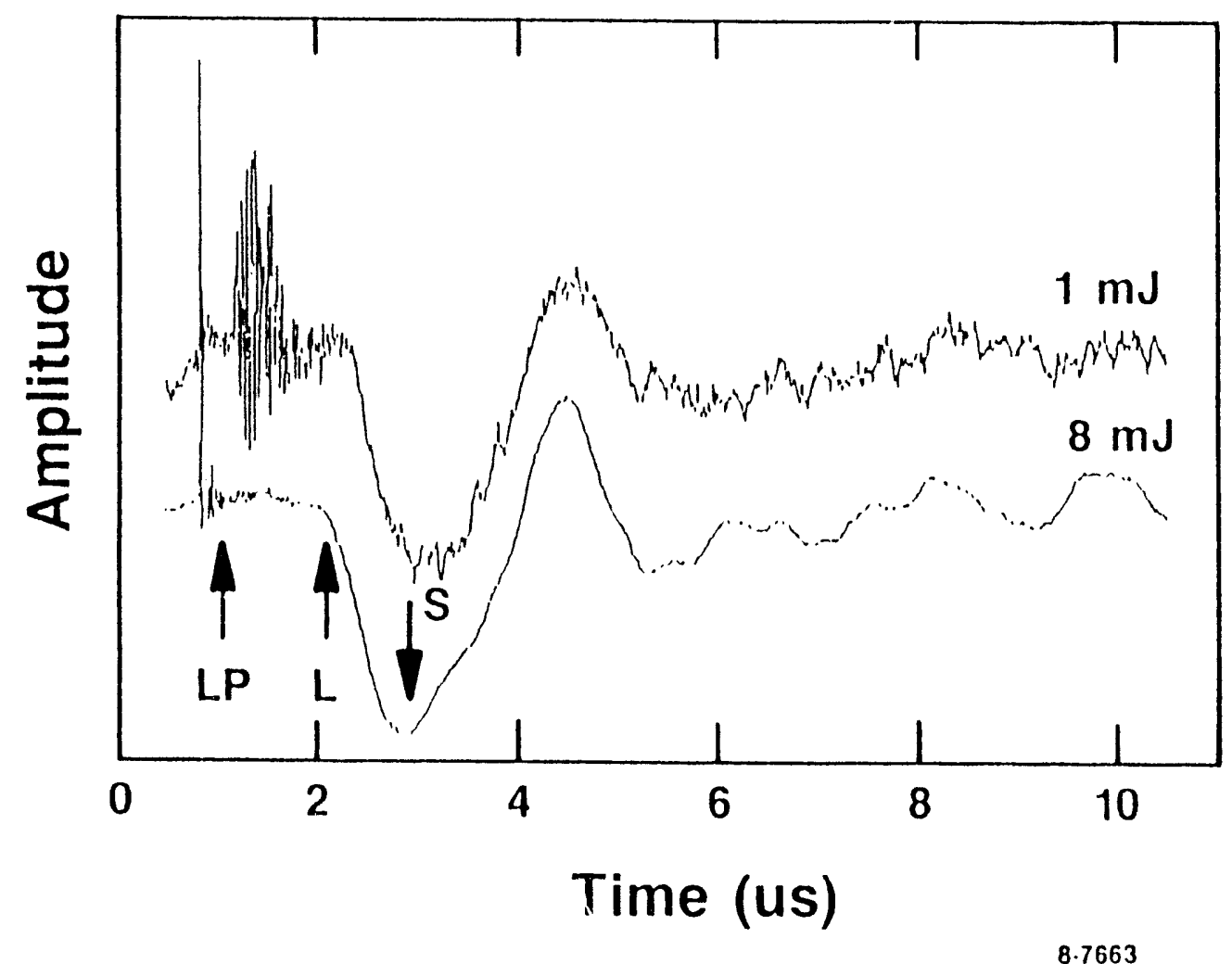

Figure 2. Typical ultrasonic pulses produced by thermoelastic conversion of a $1 \mathrm{~mJ}$ and an $8 \mathrm{~mJ}$ laser pulse incident on a $\mathrm{SiC} / \mathrm{SiC}$ composite plate and detected at the opposite face by a capacitive transducer. The arrow LP indicates the laser pulse time, while L and S indicate the arrival times of the longitudinal and shear components of the ultrasonic pulse. 
Figure 3 shows the dependence of the energy of the transmitted ultrasonic pulse on the incident laser pulse energy. An approximate quadratic dependence is observed, which is expected from theoretical considerations.

Aside from different overall energy levels of the transmitted ultrasonic pulses, little difference in waveform or frequency content is observed when the ultrasonic pulse is generated by ablation as compared to completely thermoelastic expansion. This is true when the sample material itself or a surface coating of oil is ablated. Although it is known that ablation is more efficient than thermoelastic conversion in generating high frequencies, the higher frequencies are obviously not transmitted by the material. From this, it can be concluded that the material can be effectively inspected using the laser thermoelastic generation method, without any surface damage or oil coating.

\section{Acousto-Ultrasonics}

\section{Experimental System}

The acousto-ultrasonic (AU) technique was developed by Vary and coworkers ${ }^{3}$ to characterize the mechanical properties of materials. The name of the technique stems from the fact that it is basically a hybrid between ultrasonics and acoustic emission. Two piezoelectric transducers are placed on the same side of a material sample as shown in Figure 4. An excitation pulse to one transducer generates accustic waves in the sample that are received by the other transducer, amplified, and recorded in a manner similar to conventional transmit-receive ultrasonics. The difference is that, instead of detecting a well-defined acoustic pulse traveling between the transducers, as is the case with conventional ultrasonics, a complicated superposition of wave modes and sample reverberations that resembles an acoustic emission signal is generated and detected. Examples of AU signals are shown in Figure 5. The received signals are normally processed in a manner similar to acoustic emission signals. Usually, the total number of signal "counts" (number of times the signal exceeds a fixed threshold) or the total energy content of the signal is calculated and used to characterize the sample. The results are measures of the ability of a material to support and propagate acoustic energy.

The AU measurement system used for this work employed Valpey-Fisher "pinducers," which are high-sensitivity, small-diameter $(2.4 \mathrm{~mm})$ piezoelectric transducers. These transducers were chosen primarily for their small size, which makes them ideal for point measurements. They were also chosen because they minimize perturbations to the vibration modes of the sample.

\section{Data Analysis Methods}

\section{Method of Moments}

Acousto-ultrasonic data can be analyzed by the method of moments. ${ }^{4}$ In this method, the time signal from the receiving transducer is transformed to the frequency domain using the Fast-Fourier Transform (FFT). Various moments of the frequency spectrum are then taken about the amplitude axis. For discrete data, the nth moment can be expressed as

$$
M_{n}=\sum_{i} W_{i} i_{i}{ }^{n} \Delta f
$$

where $W_{i}$ is the power spectral density at frequency $f_{i}$, and $\Delta f$ is the frequency increment. $A 1=M_{0}$ is the area under the power spectral density curve and thus is directly proportional to the energy of the signal. It is a measure of the ability of the sample to transmit acoustic energy. $A 2=M_{1} / M_{0}$ represents the centroid of the power spectral density curve, or the center frequency of the signal relative to its energy content. Comparison of $\mathrm{A} 2$ between samples reveals differences in absorption of acoustic energy as a function of frequency. 


\section{Laser Generated Ultrasound}

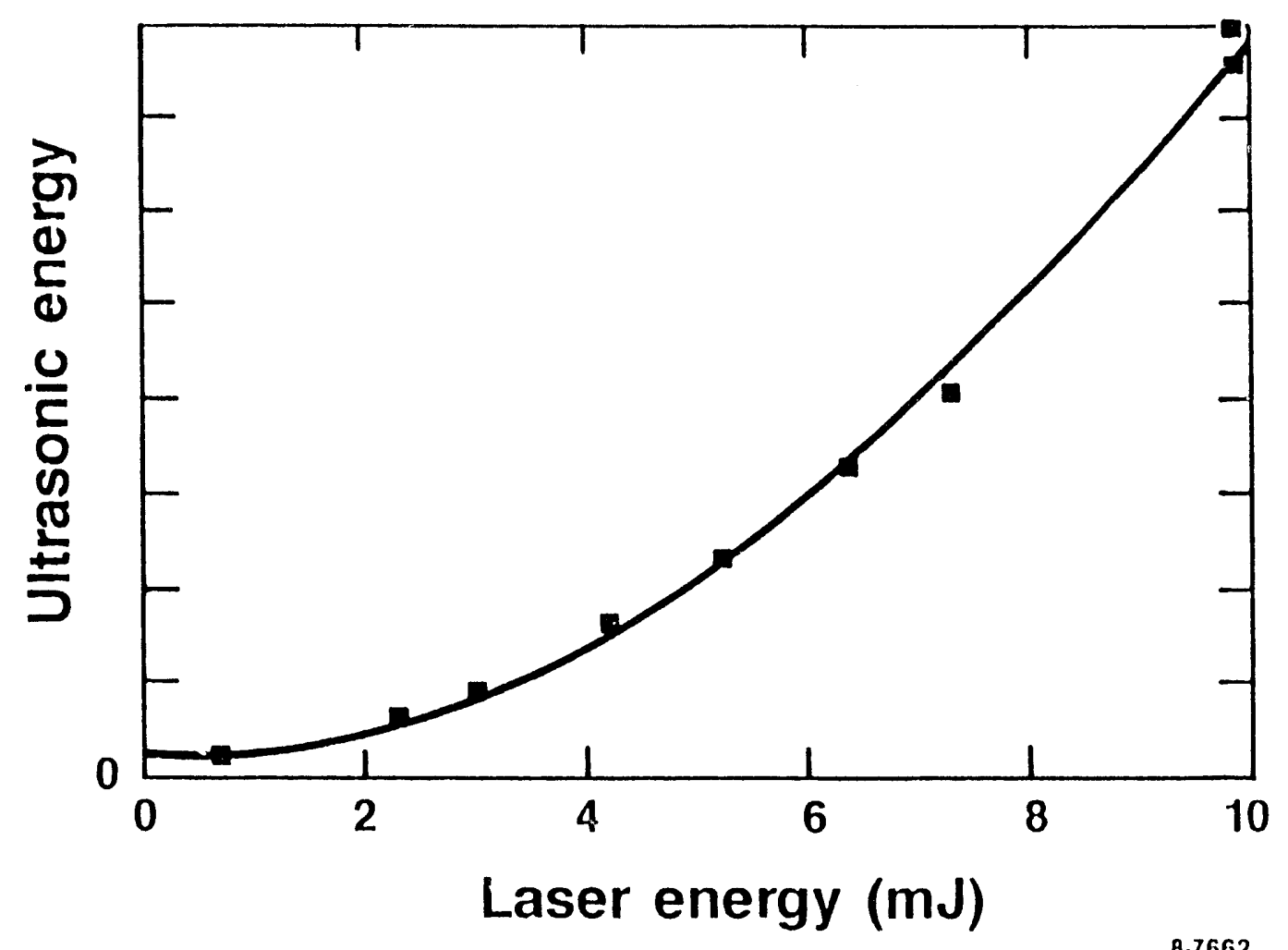

Figure 3. Ultrasonic energy in a laser-generated ultrasonic pulse as a function of the laser pulse energy. The solid line is a quadratic fit to the data points. 


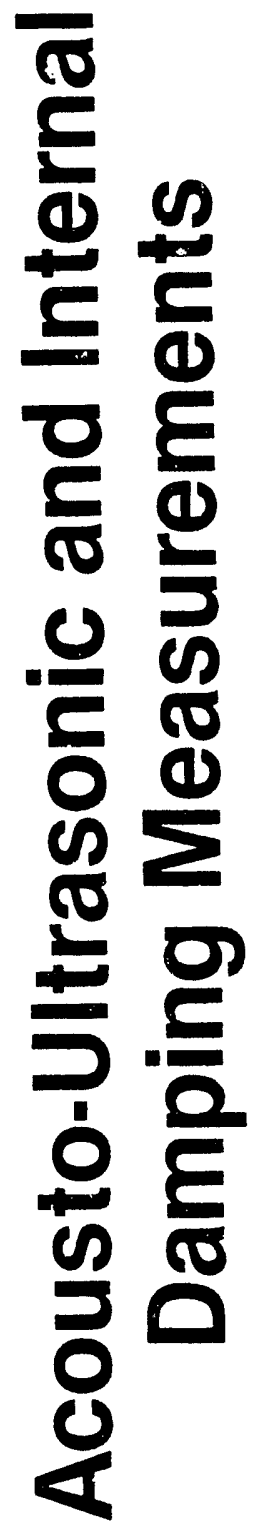




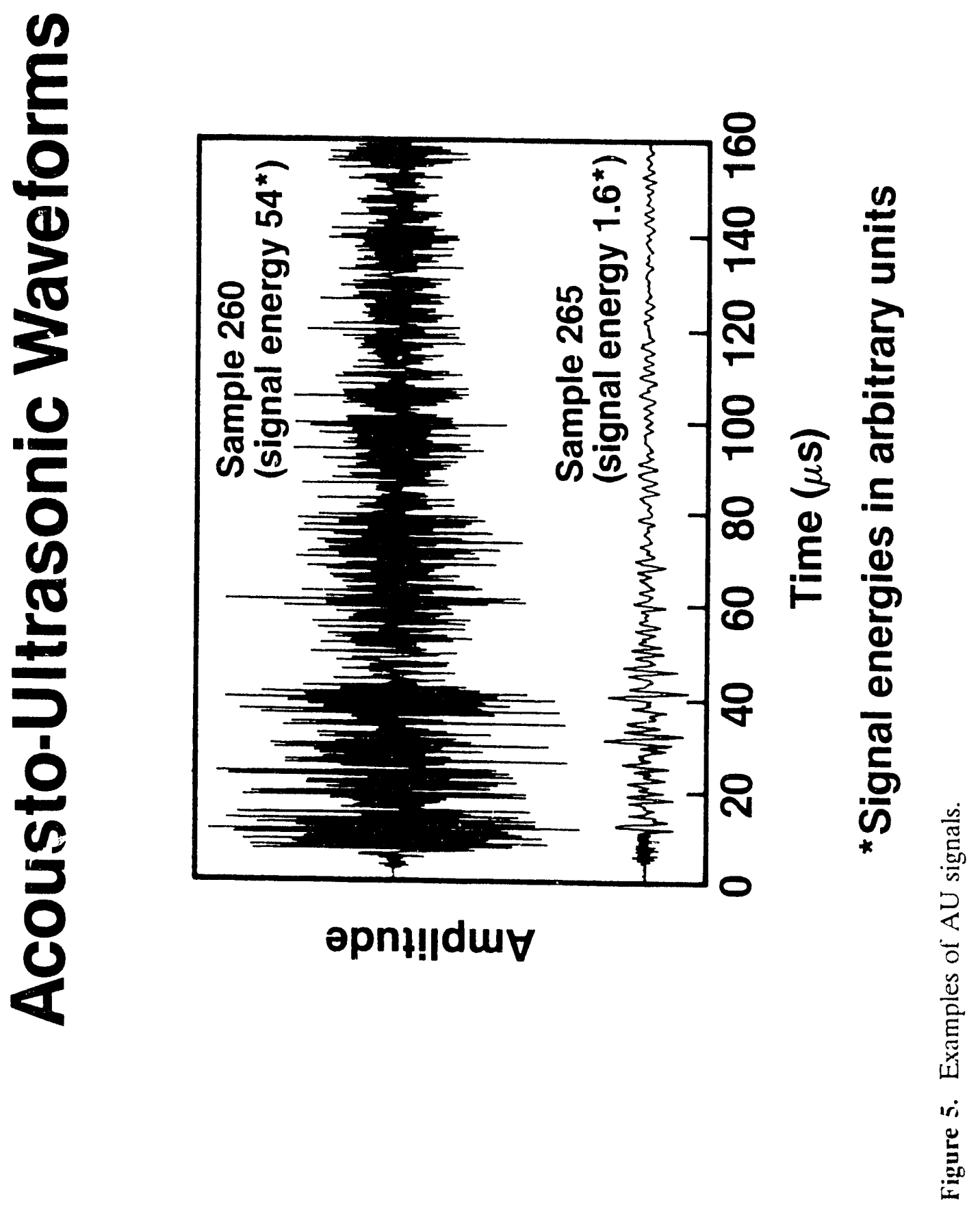




\section{Diffuse Field Decay Analysis}

A measure of the internal damping can be obtained by the diffuse field decay rate method. ${ }^{5}$ This analysis is based upon the premise that a diffuse ultrasonic field in an isolated sample will decay due only to absorption mechanisms, when the contributions of damping by air, transducers, and fixturing are minimal. The damping is measured through determination of the volume-averaged decay rate of the ultrasonic field as a function of frequency and time. A greater decay rate indicates a greater amount of internal damping or energy absorption through internal friction. The technique can be implemented using a conventional AU experimental setup. Mechanical isolation of the sample in this study was accomplished by weakly coupling the transducers to the sample, which is set on point supports. Determination of the decay rate is accomplished by dividing the recorded waveform into a number of time windows for which Fourier transforms are performed. The resulting spectrums are then broken into frequency bins and the mean square spectral amplitude is calculated for each bin. This provides a measure of the signal decay rate for individual frequency bins as a function of time. 


\section{POROSITY AND VOIDS}

\section{Porosity}

The CVI process used to fabricate the material under study can result in samples with high porosity. The reason: As the matrix material is formed in the spaces between the reinforcing fibers, further infiltration of the gaseous reactants into the interior of the sample can be inhibited. Because the presence of porosity can affect the strength of the material, NDE techniques are needed to detect and characterize the condition.

\section{Ultrasonic Attenuation}

Ultrasonic attenuation measurements were performed using the pulsed, through-transmission technique. The SiC-SiC samples used were $3.3 \mathrm{~mm}$ thick, with bulk porosity in the range 26-42 volume percent. Standard piezoelectric, broad-band, 6-mm-diameter transducers were used in both cases. The attenuation values were determined from the response of the receiving transducer with and without the sample present. A correction for reflection at the surfaces of the sample was applied treating the sample as homogeneous. (The samples are, of course, anisotropic. However, the wavelength in the sample generally exceeds $2 \mathrm{~mm}$, which is large compared to the thickness of the layers. For the higher porosity samples, where the wavelength at $2 \mathrm{MHz}$ can be as short as $1 \mathrm{~mm}$, the correction for reflection is small compared to the attenuations observed.)

Figure 6 shows the measured attenuation for six samples, ranging in porosity from $26-39 \%$ The $26 \%$ porosity sample shows an attenuation varying from $3-12 \mathrm{~dB} / \mathrm{mm}$, while the $39 \%$ porosity sample has about $10 \mathrm{~dB} / \mathrm{mm}$ greater attenuation. Figure 7 shows that, at a frequency of $1.6 \mathrm{MHz}$, the attenuation increases by about $0.5 \mathrm{~dB}$ for each percent porosity.

\section{Ultrasonic Velocity}

The propagation velocity of ultrasonic pulses in the samples was measured with the throughtransmission arrangement. The ultrasonic pulses are distorted by the sample, because the higher frequencies are preferentially attenuated. Therefore, the delay was measured between the leading edges of the pulses. The accuracy of the delay measurement was about $10 \mathrm{~ns}$, the digitizing period of the transient recorder used, which corresponds to an accuracy in the velocity of a few percent.

Figure 8 shows a strong dependence of propagation velocity on porosity for six samples having porosities ranging from $25-40 \%$. The error bars show the standard deviation of the measurements for an array of points distributed over the central region of the sample and indicate the degree of nonuniformity in the sample. Porosity was calculated from the bulk density of the sample and represents the average porosity in the sample.

\section{Ultrasonic Transmittance}

The ultrasonic energy transmitted through a sample was examined using conventional piezoelectric transducers for generation and detection of ultrasound and with laser thermoclastic generation. The transmitted energy includes the ultrasonic energy in the primary pulse that reaches the receiving transducer. It is determined by the content of the initial ultrasonic pulse, the thickness and frequency dependent attenuation of the sample, and coupling efficiency of the ultrasonic pulse into and out of the sample. The content of the ultrasonic pulse and the coupling efficiency will not change with position on the sample. The technique is intended for samples of uniform thickness, for which variations in the transmitted energy will reflect differences in the attenuation.

Good correlation is seen between the transmitted energy and the porosity of the material using the piezoelectric setup; however, the thermoelastic arrangement couples more acoustic energy into 


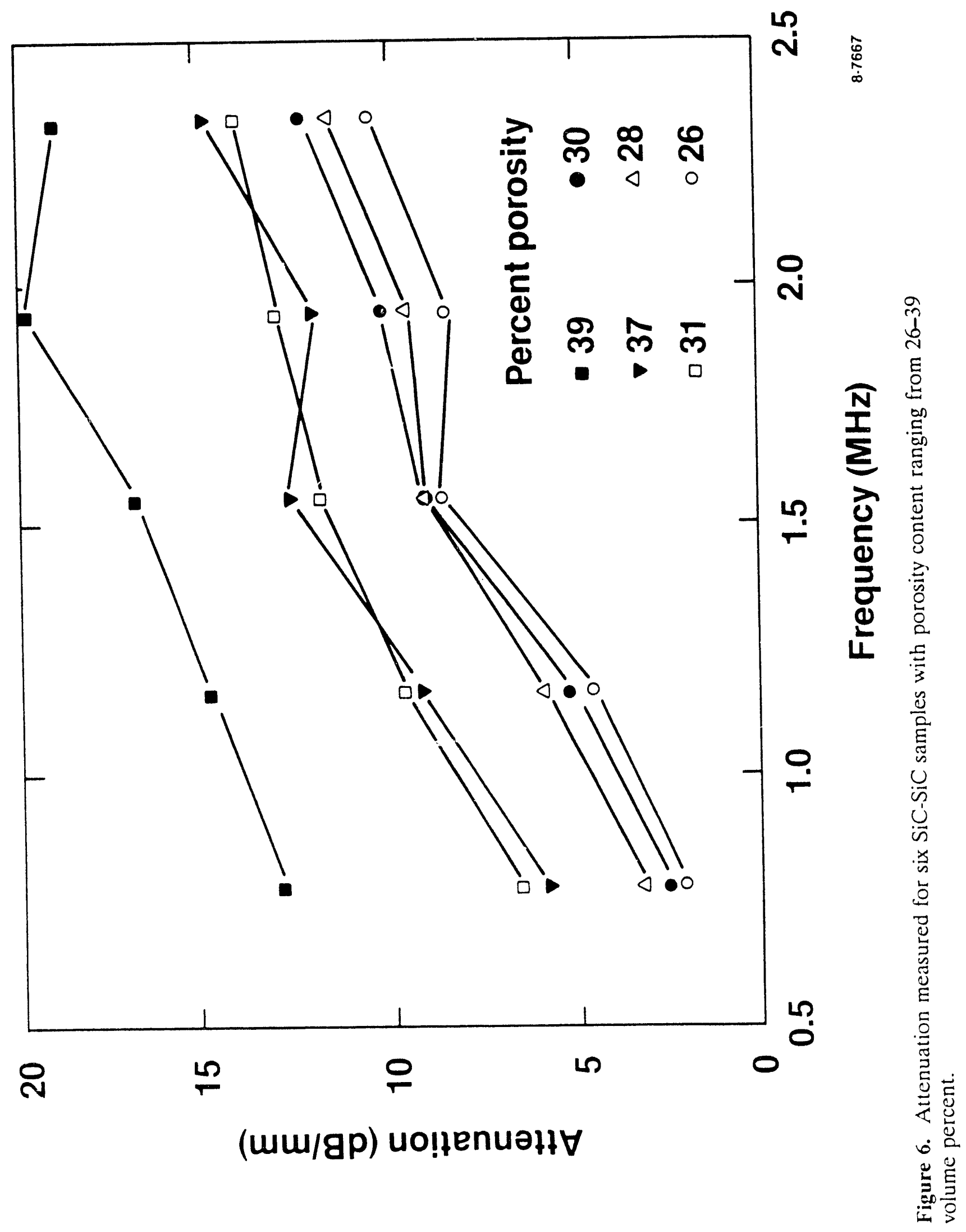




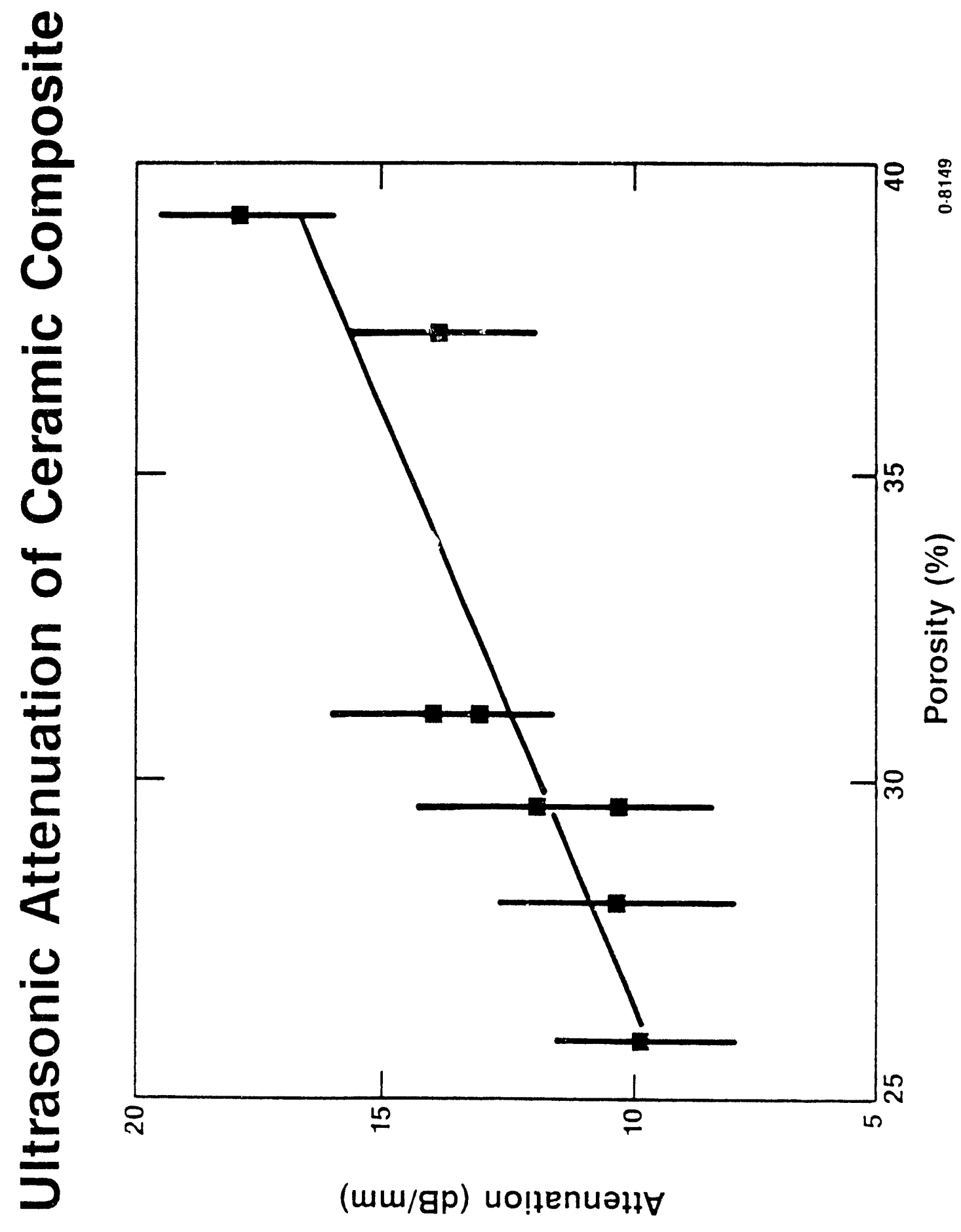

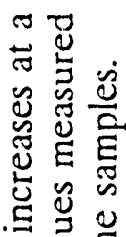

롣

웡

วี. ำ

要主

○ 总岂

-

$\frac{7}{5}$

它

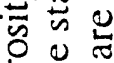

응

등 记 足号 กิ प 웡

ธิ

O 0

氖总

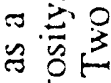

궁.

之o

ำ

늘

$5 \stackrel{5}{5}$

苛. 


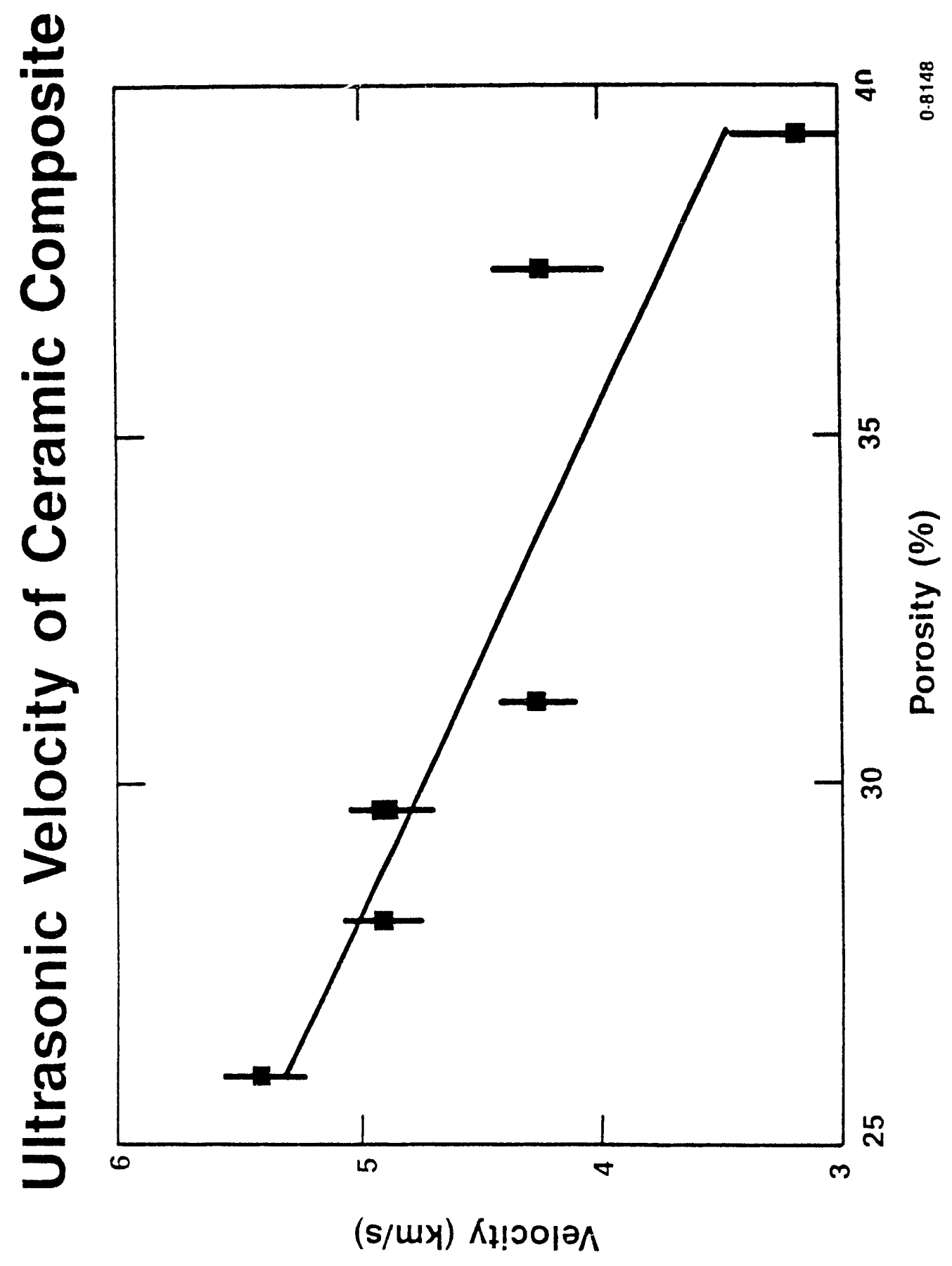

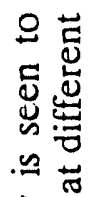

룽

를

2

ह่ ฮิ

究

入 灾㟧

모

을 牙

口 ए

믕 뭉

莕导

욤

80

运

营参

논

जै

巳

릉

는

导可

足

牙尔

도

$\infty$ is 5

늘.

종ㅁㅁ용 
the sample, thereby providing improved results. Increases of approximately $15 \mathrm{~dB}$ were observed in the received signal levels compared to the piczoclectric setup. This has resulted in improved characterization of all samples.

Samples representing a range of porosities were characterized using the laser generation system. The laser beam was defocused to about a 6-mm-spot size to minimize effects from surface roughness (and inhomogeneities on the order of the fiber bundle spacing of $1 \mathrm{~mm}$ ).

\section{Area Scans}

The transmitted energy and propagation velocity measurements can readily be employed in scans of samples, resulting in maps of the sample that can be correlated with radiographic examinations. Part $\mathrm{A}$ of Figure 9 shows a positive print of an $\mathrm{x}$-ray radiograph of a sample having large variations in porosity. Measurements of the film density, calibrated with penetrameters included in the exposure, reveal that the porosity varies from $31 \%$ in the dark region to $43 \%$ in the light region. Ultrasonic scans with $2.25 \mathrm{MHz}, 6-\mathrm{mm}$-diameter transducers show the same pattern. Part B of Figure 9 shows a map of the transmitted energy, with regions of higher ultrasonic transmittance appearing darker. Part $\mathrm{C}$ of Figure 9 shows a map of the propagation velocity, with regions of higher velocity appearing darker. In all three parts, a darker band is seen that curves from the upper left, across the middle, to the upper right of the sample.

Despite the clear correlations evident between the radiographic and ultrasonic measurements, it should be noted that the techniques do not measure the same properties. While radiography measures density, the ultrasonic techniques measure how well and how fast ultrasonic energy is propagated through the material. The ultrasonic measurements depend on the structure of the material in addition to the overall density. Ultrasonics is therefore capable of providing additional detailed information about the characteristics of porosity as determined by radiography.

\section{Void Detection}

The work described above on ultrasonic detection of porosity was concerned with the collective behavior of a large number of pores, either too small or too closely spaced to be individually resolved. The detection and characterization of large voids or agglomerations of small pores is also of importance. The ability of ultrasonics to resolve these phenomena against a background of distributed porosity was the topic of this phase of the study.

Figure 10 is an $x$-ray radiograph of a sample containing seeded internal voids. The sample, prepared at Oak Ridge National Laboratory, was $45 \mathrm{~mm}$ in diameter, $11.5 \mathrm{~mm}$ thick, contained $40 \%$ by volume of Nicalon plain weave cloth in a 30-60-90 layup, and was about $85 \%$ of theoretical density. The voids were nominally 2 and $5 \mathrm{~mm}$ in diameter, $2.5 \mathrm{~mm}$ thick, and were located about $2 \mathrm{~mm}$ from opposite surfaces of the sample. Inspection was performed with focused, broad-band, 2.25 $\mathrm{MHz}$ piezoelectric transducers focused on the respective surfaces of the sample. This approximated point source and detection and simplified the geometry of the inspection. The ultrasonic response of this sample is shown in Figure 11 for three cases, when the transmitted beam is unobstructed and when it encounters the $2-\mathrm{mm}$ and $5-\mathrm{mm}$ voids, respectively. The vertical dotted lines show the portion of the signals for which the transmitted ultrasonic energy was calculated. Within these limits. the waveforms are similar, with only the signal amplitudes affected by the presence of the voids.

Figure 12 shows an ultrasonic transmitted energy c-scan image of the sample. Both voids are clearly visible. The seeded internal voids are also seen in Figure 13, which is a line scan taken along a sample diameter containing both voids. The transmitted ultrasonic energy dips by about 10 and 6 $\mathrm{dB}$ for the two voids. A similar line scan for an identical sample containing no voids contains fluctuations of about $2 \mathrm{~dB}$ caused by variations in sample porosity and reinforcement. It appears that the $2-\mathrm{mm}$ void is close to the limit of resolution; although smaller voids might be detected, their size 


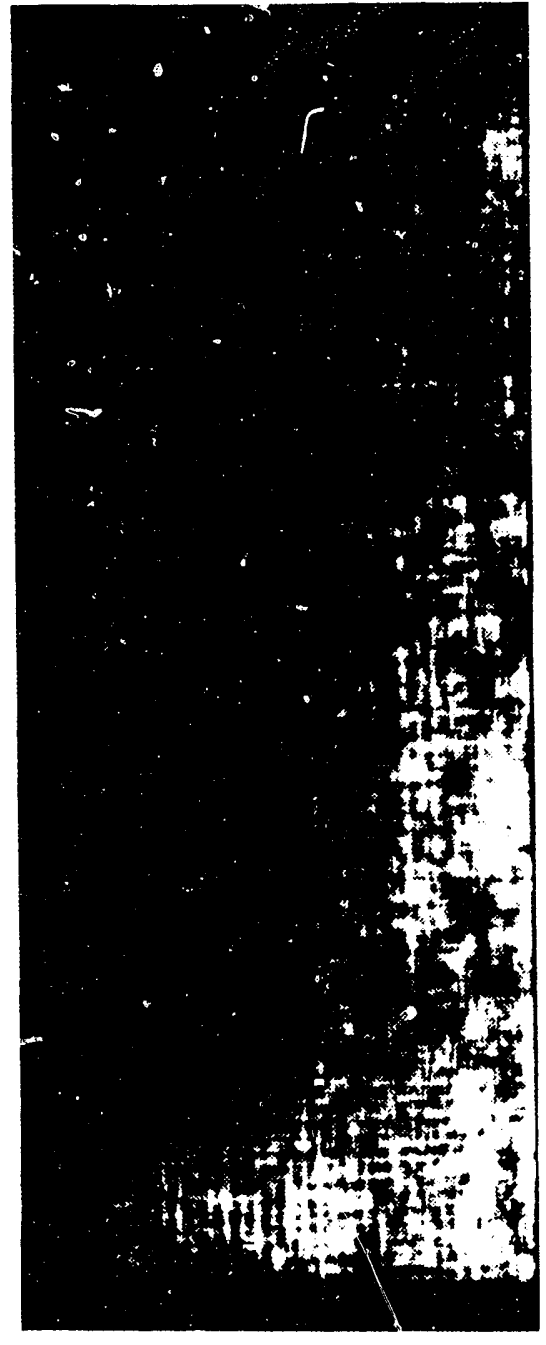

(a)

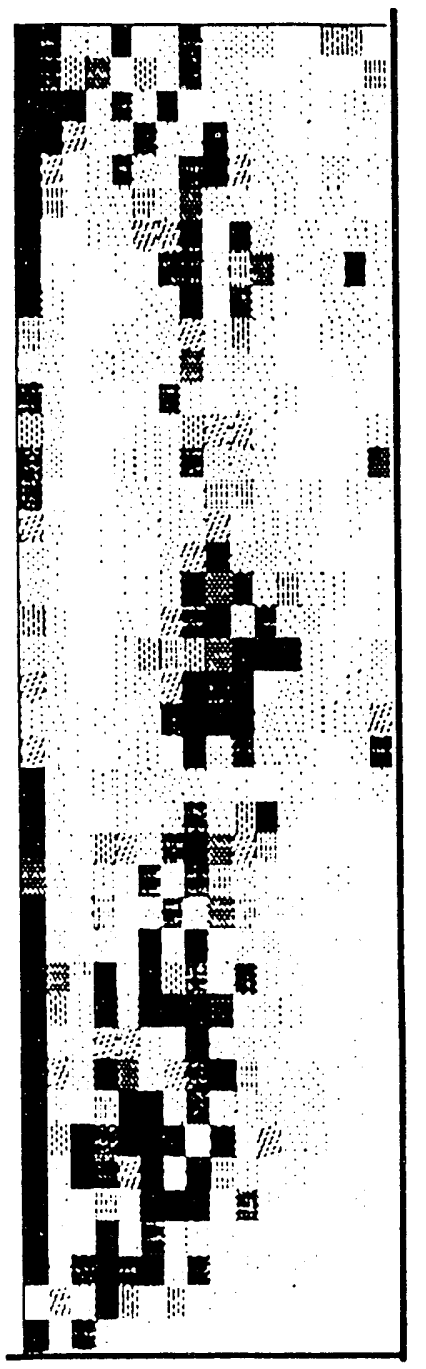

(b)

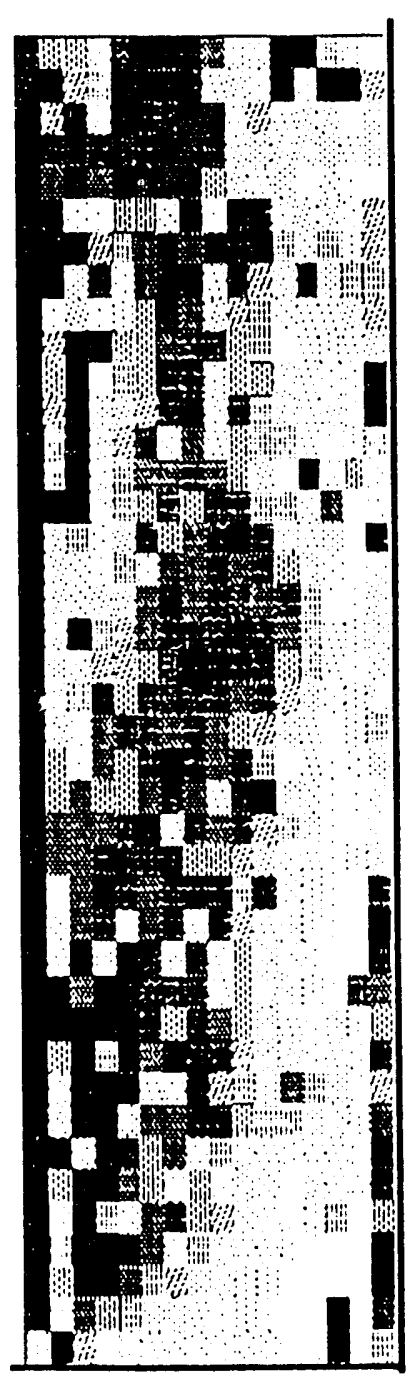

(c)

Figure 9. A. Positive image of $\mathrm{x}$-ray radiograph of a $\mathrm{SiC}$-SiC sample containing large variations in porosity. Porosity varies from $31-43 \%$.

B. Map of the transmitted ultrasonic energy for the sample in Figure 5. The darker areas have higher transmitted energy.

C. Map of the ultrasonic propagation velocity for the sample in Figure 5. The darker areas have higher velocity. 


\section{X-ray Radiograph}

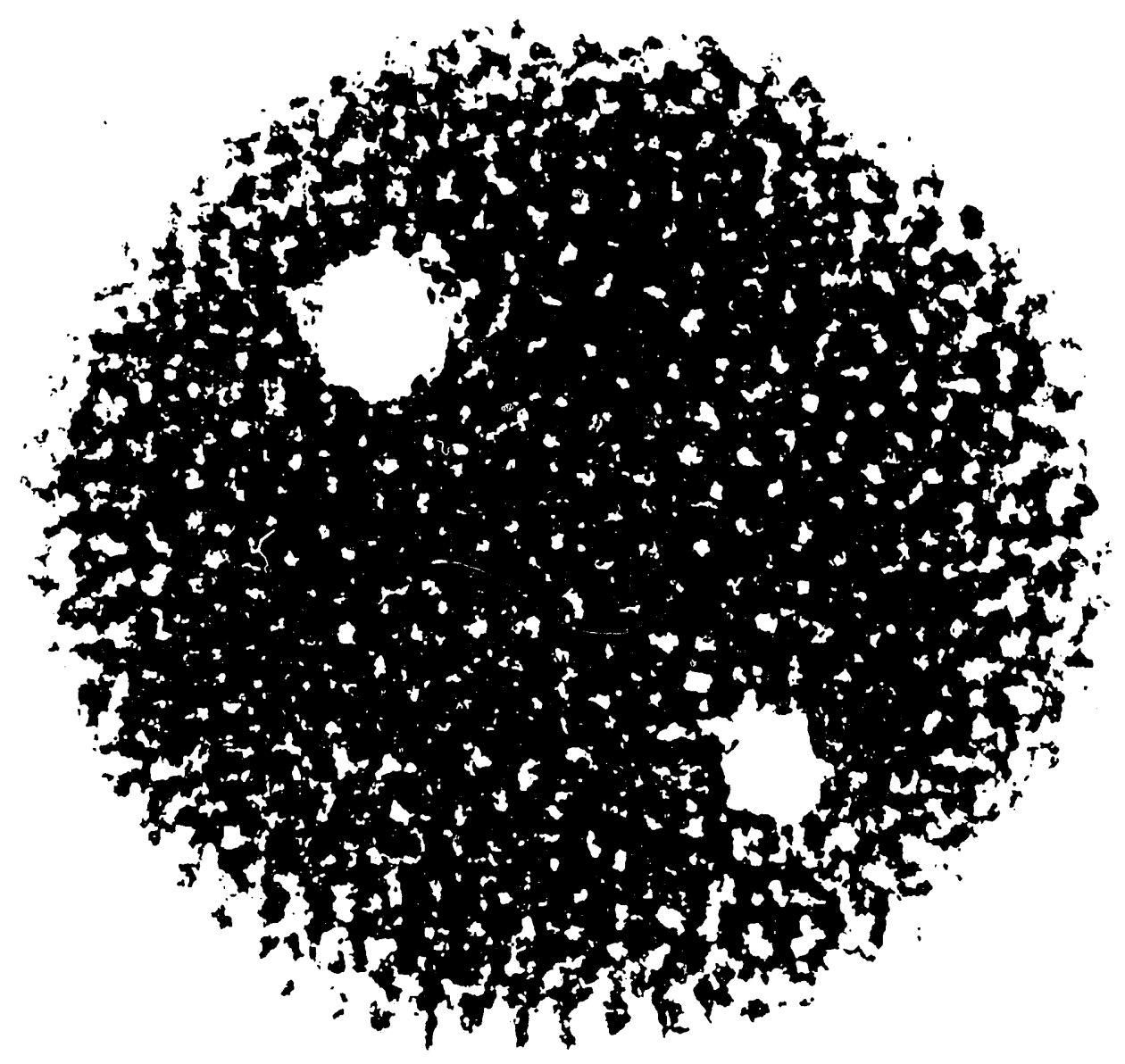

Figure 10. X-ray radiograph of ORNL sample containing seeded voids. 


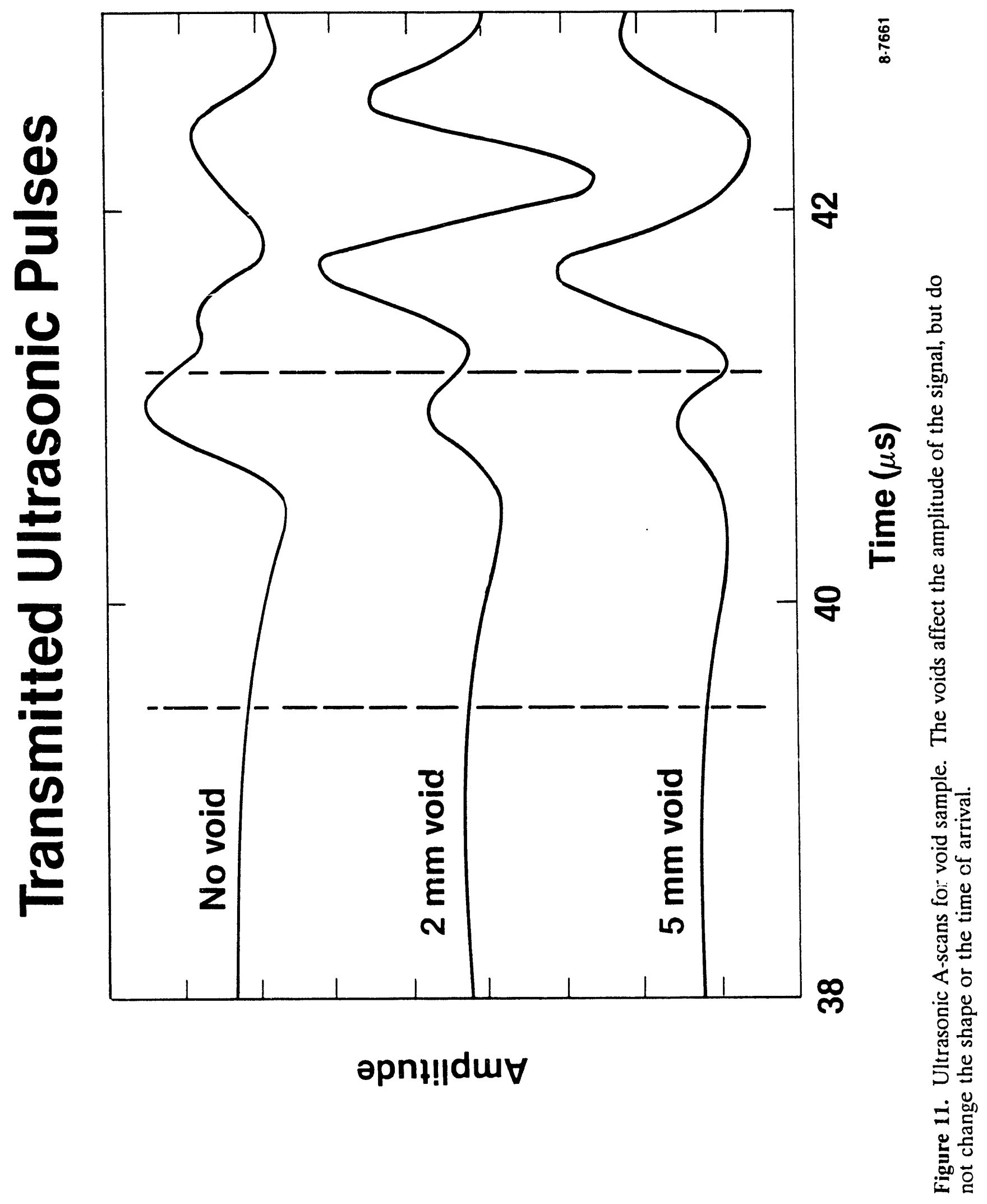




\section{Transmitted Energy}

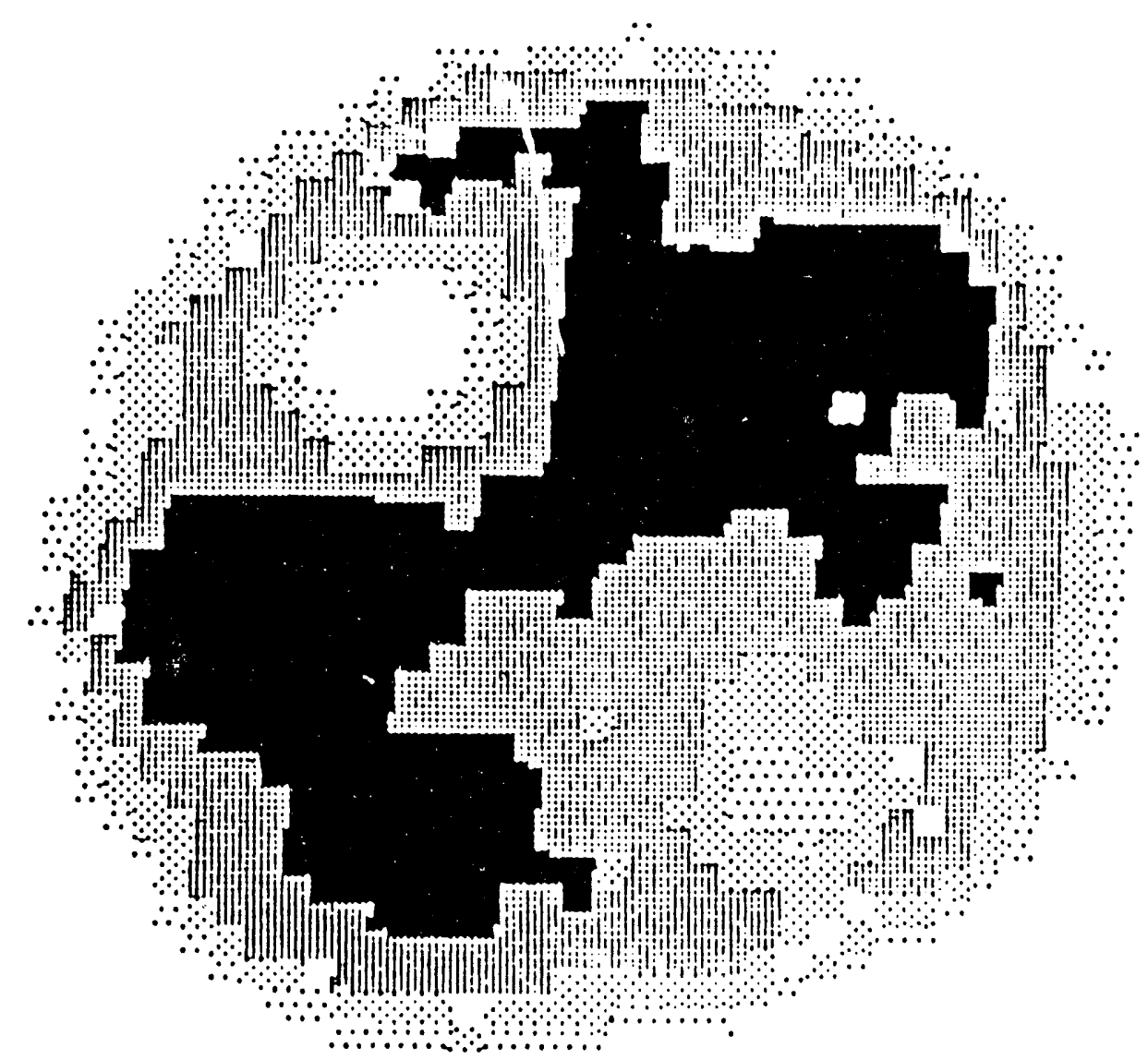

\section{$48 \mathrm{~mm}$ diameter, $11.5 \mathrm{~mm}$ thick}

\section{Voids $5 \mathrm{~mm}, 2 \mathrm{~mm}$}

8.9369

Figure 12. Transmitted ultrasonic energy image of seeded void sample. 


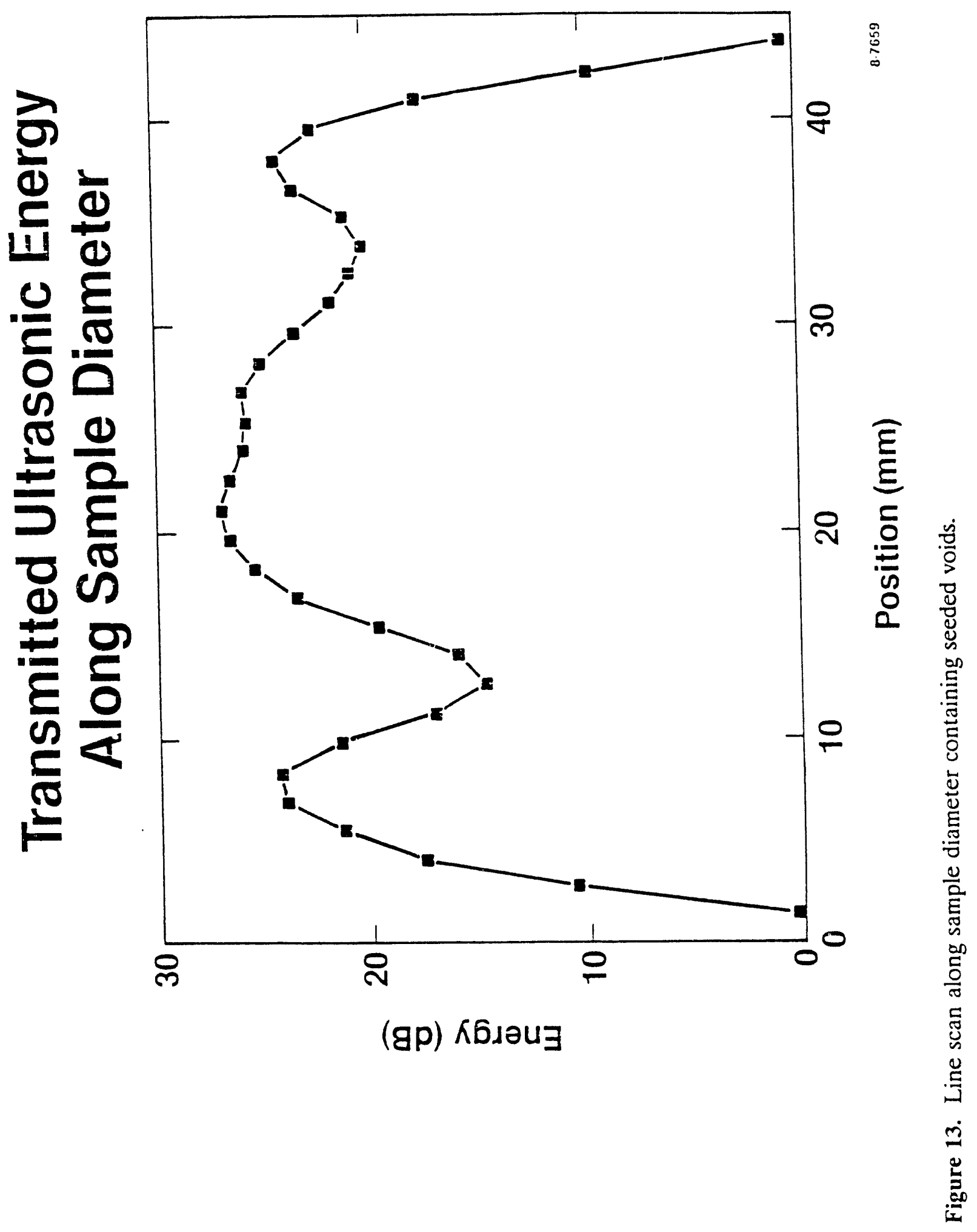


could not be accurately determined from such c-scans nor could it be determined whether there was a single large void present or several smaller closely spaced voids. This is not surprising, since the ultrasonic wavelength in the sample is approximately $3.5 \mathrm{~mm}$ and the periodicity of the reinforcing weave is about $1.5 \mathrm{~mm}$. However, since the time of arrival of the transmitted ultrasonic pulse is insensitive to the presence of a void, as shown in Figure 11, it should be possible to distinguish voids from variations in material porosity. It is concluded that voids as small or smaller than the wavelengths of ultrasound, which can propagate through the material, can be detected; but the reinforcing fibers and porosity are the limiting parameters. 


\section{MECHANICAL DAMAGE CHARACTERIZATION}

Acousto-ultrasonics has been successful in characterizing physical damage such as fiber breakage and matrix cracking in composites including graphite/epoxy and glass/epoxy laminates. ${ }^{6}$ The ability of the AU diffuse decay rate analysis method to detect damage in ceramic matrix composites has been investigated and compared with conventional vibration response measurements, a wellaccepted technique that requires samples of certain geometry and measures the response at the natural mode frequencies of the sample.

The samples, obtained from Refractory Composites, Inc., Whittier, California, were in the form of plates measuring approximately $90 \times 25 \times 2.5 \mathrm{~mm}$. They were fabricated from preforms of inultiple layers of Nicalon $\mathrm{SiC}$ cloth, with the $\mathrm{SiC}$ matrix added by chemical vapor infiltration. The samples tested had approximately $30 \mathrm{vol} \%$ fiber content. Cracking and crushing of the matrix was the primary damage produced at the impact energies tested. Mechanical impact damage was produced by placing samples on a solid backing plate and dropping steel balls of known masses onto the samples from a measured height.

\section{Acousto-Ultrasonic Measurements}

AU measurements were made, on several samples in the undamaged state, and after dropping each of five steel balls having masses increasing from $0.02 \mathrm{Kg}$ to $0.5 \mathrm{Kg}$ from a height of $1 \mathrm{~m}$. Figure 14 shows the results of the AU measurements for a typical sample. AU decay rate is plotted vs. frequency for the different degrees of accumulated impact damage. The undamaged state is denoted by $u$, the damage produced by the smallest ball by 1 , and the accumulated damage produced by successively dropping all 5 balls by 5 . The observed AU decay rate response is complex. An increase in $\mathrm{AU}$ decay rate over the undamaged state is initially observed for the smallest aegree of damage as would be expected. However, for increasing damage, the AU decay rate decreases and different changes with frequency are observed. At present, this behavior is not entirely understood. Additional work is necessary to determine under what conditions and range of damage the AU technique can reliably assess impact damage in this material.

\section{Vibration Response Measurements}

In addition to acousto-ultrasonics, conventional methods of taking vibration response measurements were made, primarily for comparison purposes. The method used was the measurement of the flexural vibrations of a rectangular sample vibrating in the first fundamental mode. This is accomplished by supporting a sample on two knife-edge supports and giving it an impulsive excitation by a small mechanical impact at the center of the sample. Sample vibrations are measured with a magnetic or piezoelectric sensor located near one end. The separation of the knife edges is set to allow support of the sample at the nodes of the fundamental "free-free" vibration mode, namely $0.224 \mathrm{~L}$ from eachit end, where $\mathrm{L}$ is the overall sample length. The experimental setup is shown in Figure 15.

Signals from the vibration sensor are digitized and transformed to the frequency domain with an FFT. The absolute frequency of an observed resonance peak is related directly to the elastic modulus of the sample, while the width of the peak at half power, defined as the loss factor, is a measure of the internal damping. ${ }^{7}$

Vibration measurement results for the same sample for which AU results are shown in Figure 14 are shown in Figure 16, in which the amplitude of vibration for the first fundamental flexural mode is plotted as a function of frequency. This shows the expected behavior in which the resonant frequency, a measure of the effective elastic modulus of the sample, decreases with increasing damage, while the width of the resonance peak, a measure of internal damping in the material, increastes. Vibratioñ measuirments for four difforent samples are shown in Figures 17 and 18 , in 


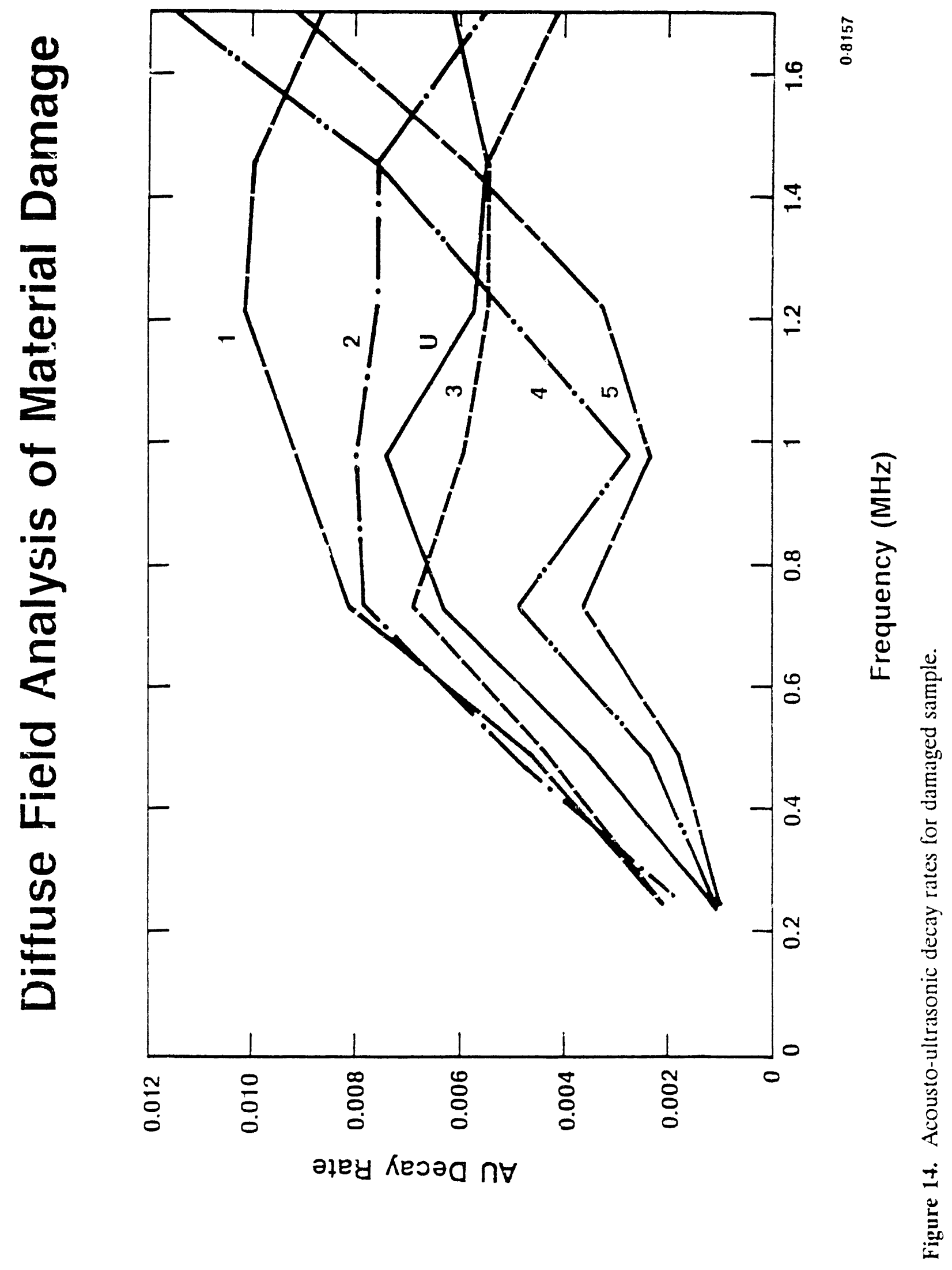




\section{Vibration Analysis}

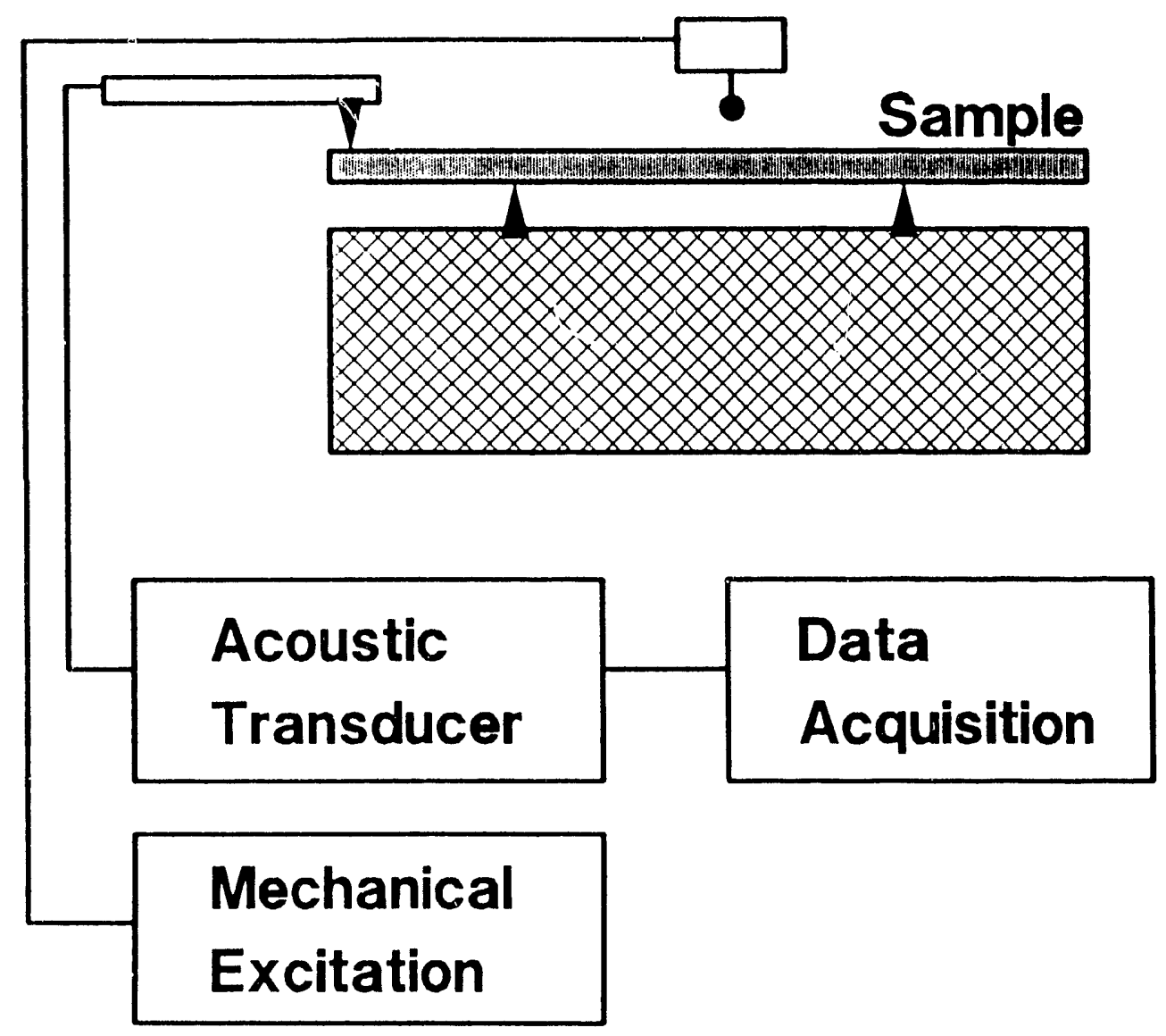

Figure 15. Vibration response measurement setup. 


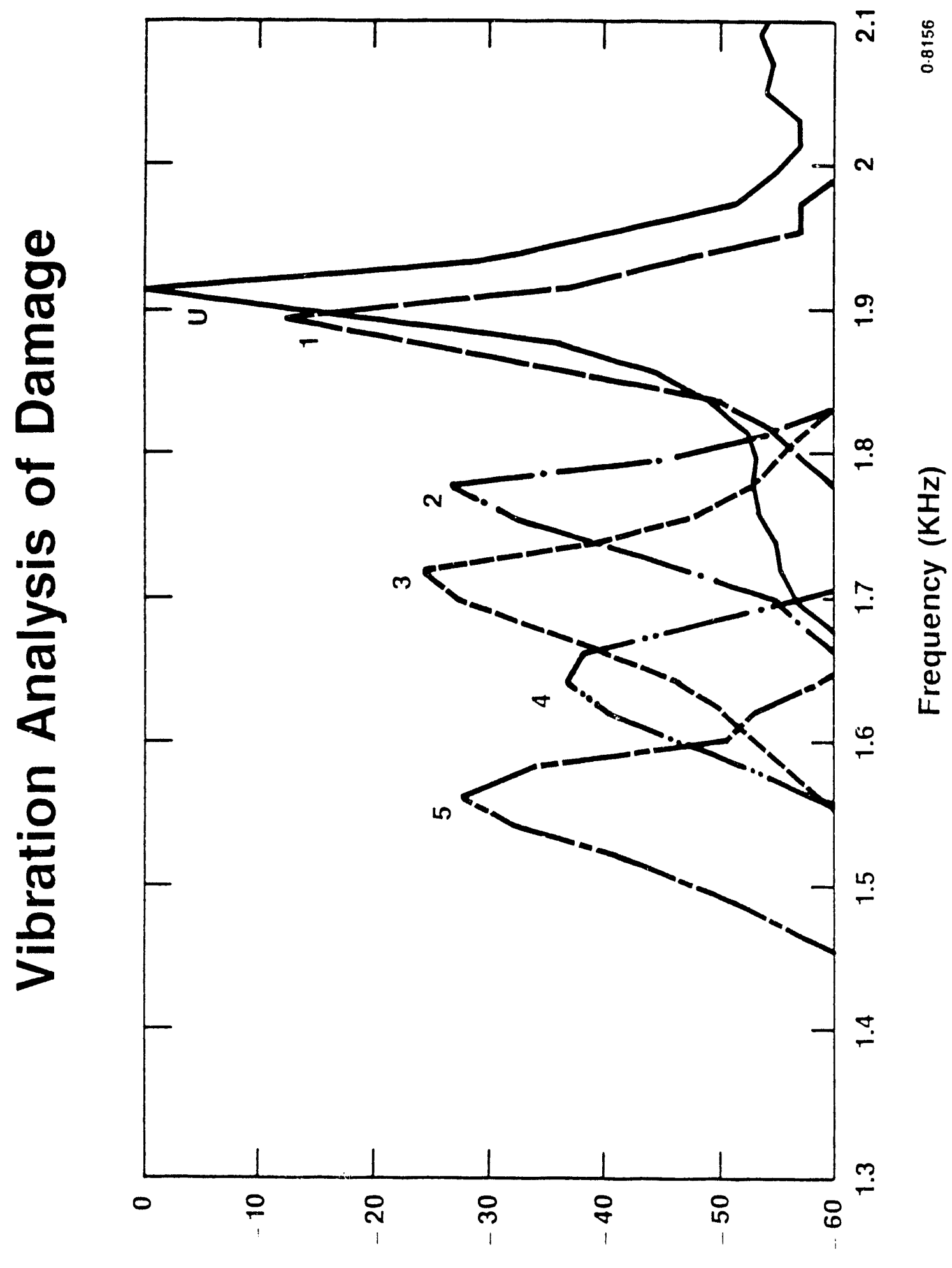

苍

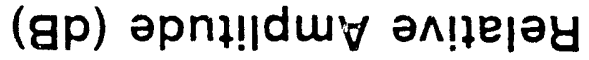




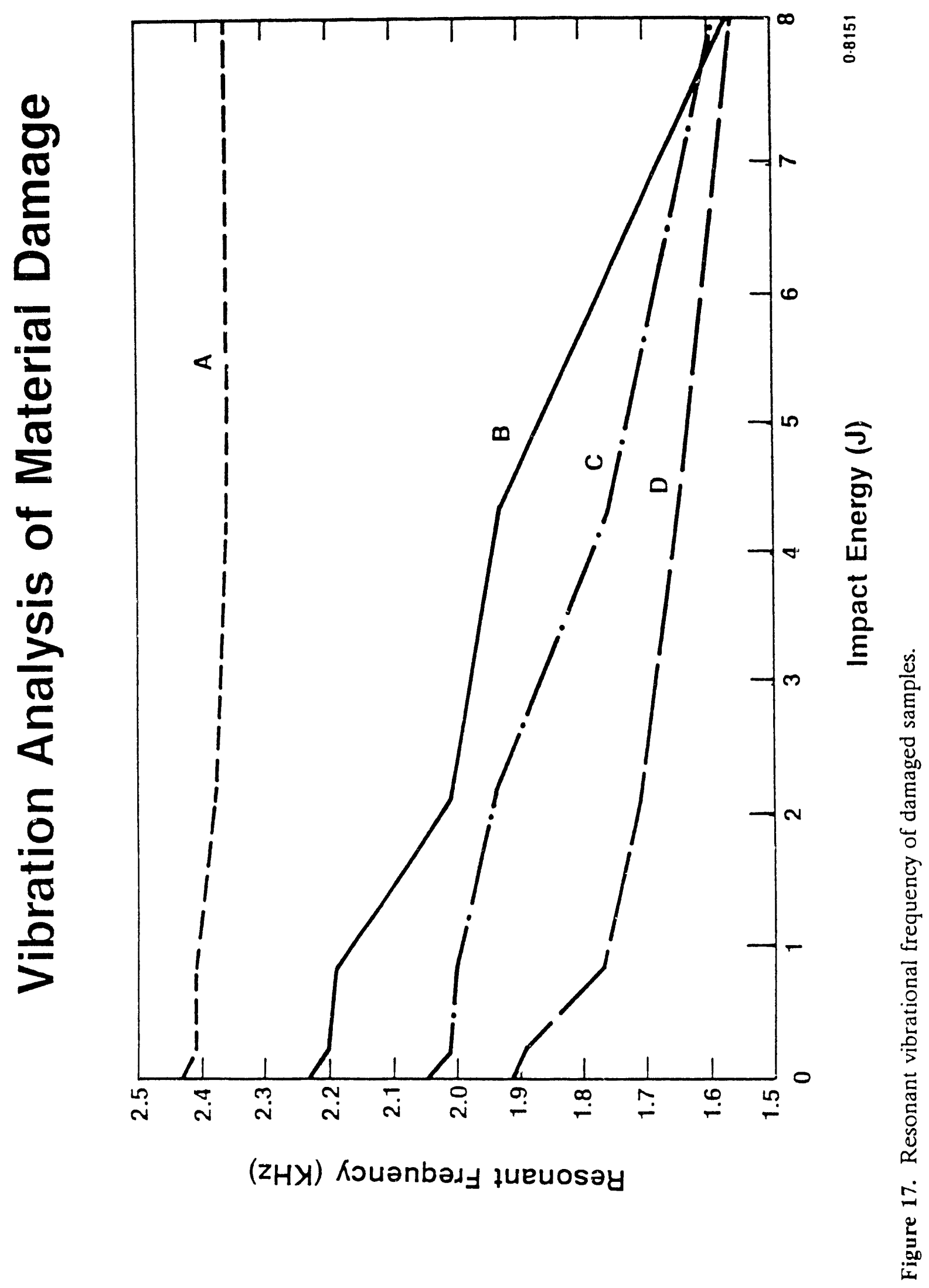




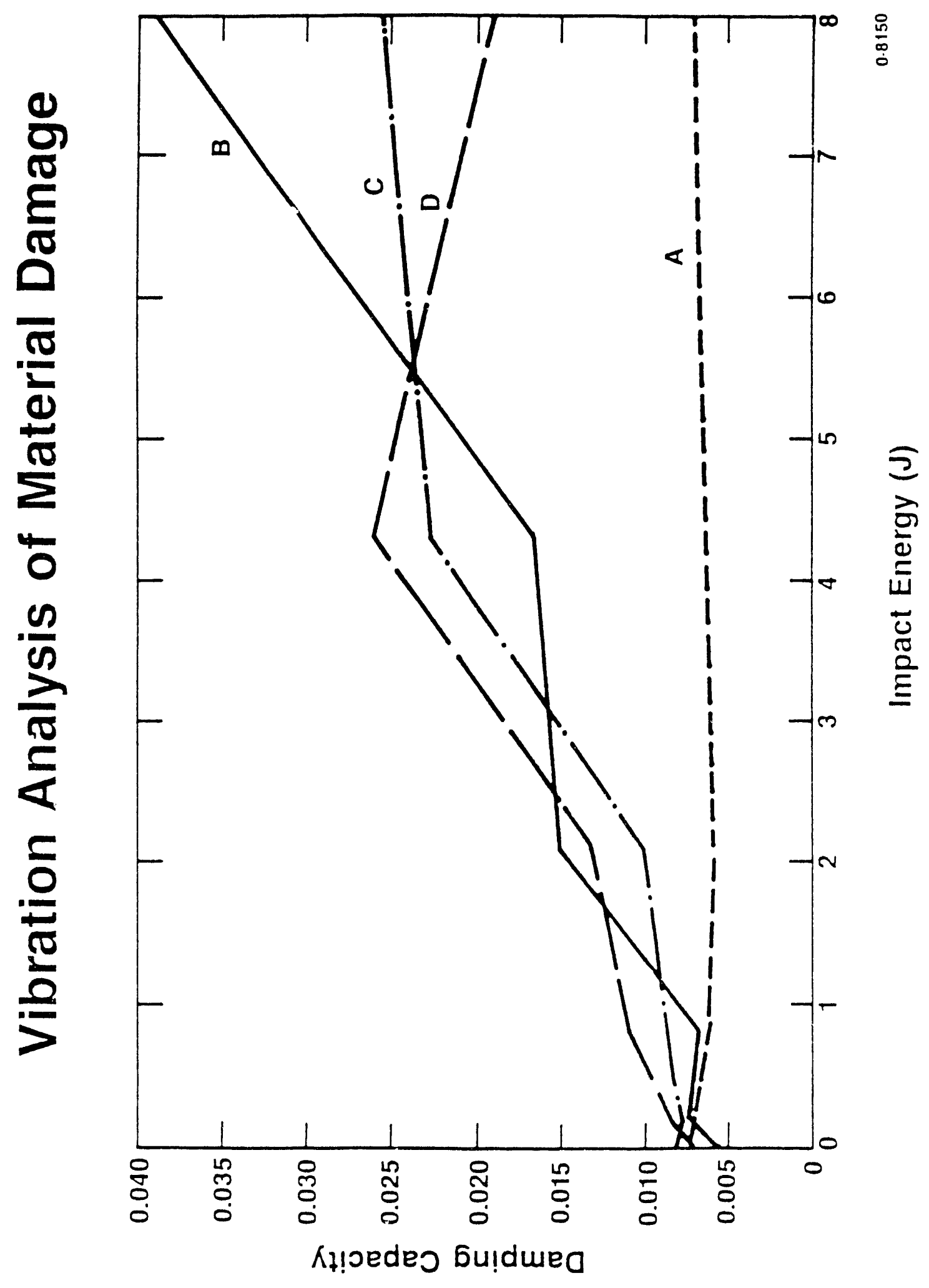

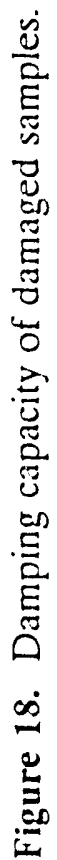


which the vibration parameters are plotted for each sample against cumulative impact energy, as calculated from the mass of each ball and the height from which it was dropped. Figure 17 shows the decrease in resonant frequency, or effective elastic modulus, observed with increasing damage energy, and Figure 18 shows the increase in damping. Note that sample $A$ is relatively unaffected by the impact. Visual inspection showed Sample $A$ to be relatively undamaged compared to the other samples. The sample was apparently tougher than the others, absorbing less energy from the impacts. 


\section{FIBER-MATRIX INTERFACE CHARACTERIZATION}

\section{Introduction}

Advanced ceramic composites are currently of great interest for high-temperature structural applications, because they exhibit significantly higher fracture toughness than do monolithic ceramics. The fiber-matrix interface bond has a significant role in determining the fracture toughness of the material. Phenomena such as interface debonding, fiber slip, or pull-out, will improve material toughness by increasing the energy required to propagate a crack. ${ }^{8}$ However, a bond that is too strong permits a crack to propagate directiy through a fiber-matrix interface without being significantly impeded, resulting in brittle fracture. In a bond that is too weak, the toughening mechanisms are not significant. As a result, special processes are required in the manufacture of these materials to achieve optimum fiber-matrix bonding. ${ }^{9}$ Effective NDE techniques capable of characterizing the fiber-matrix interface are needed to maintain control of the manufacturing process and to ensure the quality of fabricated components.

\section{Material Samples}

Composite specimens were supplied by Oak Ridge National Laboratory (ORNL) for this investigation. The material consisted of a $\mathrm{SiC}$ matrix with a continuous fiber reinforcement of $2-\mathrm{d}$ weave Nicalon (Nippon Carbon Co., Tokyo, Japan) cloth layered in a 30-60-90 pattern. A chemical vapor infiltration (CVI) process was employed to form the matrix. The specimens were in the form of right circular cylinders $45 \mathrm{~mm}$ in diameter and $11.5 \mathrm{~mm}$ high, with $40 \mathrm{vol} \%$ fiber and $85 \%$ of theoretical density.

Specimens with strong, intermediate, and weak interface bond strengths were fabricated. A weak interface bond was produced by coating the Nicalon fibers with a $0.5 \mu \mathrm{m}$ layer of carbon prior to infiltration. Following infiltration, the specimen was heat treated $\left(850^{\circ} \mathrm{C}\right)$ for two hours in flowing oxygen to oxidize the carbon interlayer. This resulted in essentially no bonding or friction at the interface. An intermediate bond strength was produced by also coating the fibers with a $0.05 \mu \mathrm{m}$ carbon layer, but no heat treatment was performed. A strong interface bond resulted, when neither a fiber precoat nor subsequent heat treatment was used. A silica layer that forms on the surface of the uncoated Nicalon fibers during initial heating during the CVI process bonds strongly to both the fiber and the deposited matrix. The relationship between fabrication parameters and interfacial frictional stress has been confirmed for such specimens. ${ }^{10}$

\section{Ultrasonic Characterization}

Ultrasonic velocity and attenuation are strongly influenced by material microstructure. For composites having acoustically similar materials for both matrix and fibers, as is the case here, it is expected that the nature of the fiber-matrix interface would strongly affect the ultrasonic properties; as the strength of the fiber-matrix interfac: bond decreases, an increase in acoustic absorption and scatter should be observed. This would result in an increase in attenuation and a decrease in velocity.

Ultrasonic velocity and attenuation measurements were made by through-transmission techniques using both piezoelectric transducers and laser-ultrasonic generation. For the piezoclectric technique, matched, broadband, contact transducers were dry-coupled to the samples using sheets of thin polyvinyl chloride to prevent errors caused by uptake of liquid couplants. A 1.5-MHz-pulsed oscillator was used to drive the transmitting transducers (center frequencies of $2.25 \mathrm{MHz}$ longitudinal, $5.0 \mathrm{MHz}$ shear). The received signals were digitized at $25 \mathrm{MHz}$ and stored for processing. Ultrasonic: velocities were calculated by measuring the sample thicknesses and the times required for the ultrasonic pulses to propagate through the samples. 
Table 1 summarizes the longitudinal and shear wave velocity measurements made transverse and parallel to the plies of the fiber reinforcing cloth. Significantly lower velocities are evident for Sample 265 (weakly bonded interface) when compared to Sample 260 (strongly bonded interface). These velocities should not be interpreted as the definitive values for this material, because they represent measurements on only two samples. Also, wave velocity measurements were difficult to make, particularly for the weakly bonded sample, of high attenuation and distorted wave forms, thereby resulting in a large experimental measurement error. Nevertheless, it is felt that the measured differences in the two samples are indicative of the differences that exist in fiber-matrix bonding. Note that the measured shear wave velocity perpendicular to the plies in Sample 265 was slightly greater than the longitudinal wave velocity, a physically impossible result for isotropic materials. However, for this extremely complex and anisotropic material, no conclusion can be reached at this time about this result.

As illustrated in Figure 19, Sample 265 also demonstrates a significantly higher signal attenuation $(+80 \mathrm{~dB})$. Because both samples are similar in density and fiber content, the measured differences in acoustic properties are attributed to the differences in interface bonding.

More repeatable resulis were obtained using the noncontacting laser-ultrasonic technique, although experimental limitations permitted only acoustic pulses propagating through the sample in a direction perpendicular to the fiber plies. A pulsed Nd:YAG laser beam generated an acoustic pulse at one surface of the samples, and a capacitive sensor detected the transmitted pulse at the opposite sample surface. As with the contact transducer measurements, ultrasonic velocities were determined from the sample thicknesses and from the measured transit times for the ultrasonic pulses through the samples.

Table 2 summarizes the longitudinal wave velocities measured by the laser-ultrasonic technique in three samples. As can be seen, the expected decrease in velocity with decreasing fiber-matrix interface bond strength was observed. A significantly lower velocity is evident for Sample 265 (weakly bonded interface) when compared to Sample 260 (strongly bonded interface). An intermediate ultrasonic velocity is associated with the sample having the intermediate bond strength. Because the three samples are similar in density and fiber content, the measured differences in acoustic properties are attributed to the differences in interface bonding.

\section{Acousto-Ultrasonic Response}

\section{Introduction}

Mcasurements of ultrasonic wave velocity and/or attenuation can potentially detect differences in the fiber-matrix interface condition, as demonstrated by the ultrasonic results. This is because ultrasonic propagation in a material is affected by differences in acoustic impedance at interfaces. However, as has been shown, ultrasonic attenuation and velocity are also strongly affected by porosity; and since porosity is often high in ceramic matrix composites, it would be difficult, if not impossible, to discriminate between porosity and fiber-matrix interface variations. Acousto-ultrasonics has the potential for obtaining more information about material microstructure than conventional ultrasonic measurements. However, acousto-ultrasonic data analysis methods that make use of only transmitted signal amplitudes are also affected by porosity. To reliably characterize the fiber-matrix interface then, a measurement technique is needed that, while sensitive to the interface condition, is relatively unaffected by porosity. 
Table 1. Ultrasonic velocities measured for strong and weak bonds.

\begin{tabular}{|c|c|c|c|c|}
\hline Sample & \multicolumn{2}{|c|}{ Strong Bond } & \multicolumn{2}{|c|}{ Weak Bond } \\
\hline $\begin{array}{l}\text { Propagation Direction } \\
\text { Relative to Plies }\end{array}$ & $\perp$ & $\mathbf{I}$ & $\perp$ & 1 \\
\hline Longitudinal Velocity $(\mathrm{mm} / \mathrm{ms})$ & 8.0 & 10.3 & 1.9 & 8.2 \\
\hline $\begin{array}{l}\text { Shear Velocity }(\mathrm{mm} / \mathrm{ms}) \\
\text { Polarization | to Plies }\end{array}$ & 5.2 & 6.6 & 2.1 & 5.5 \\
\hline $\begin{array}{l}\text { Shear Velocity }(\mathrm{mm} / \mathrm{ms}) \\
\text { Polarization } \perp \text { to Plies }\end{array}$ & 5.2 & 6.5 & 2.1 & 2.2 \\
\hline
\end{tabular}


$\stackrel{\infty}{N}$
o
.

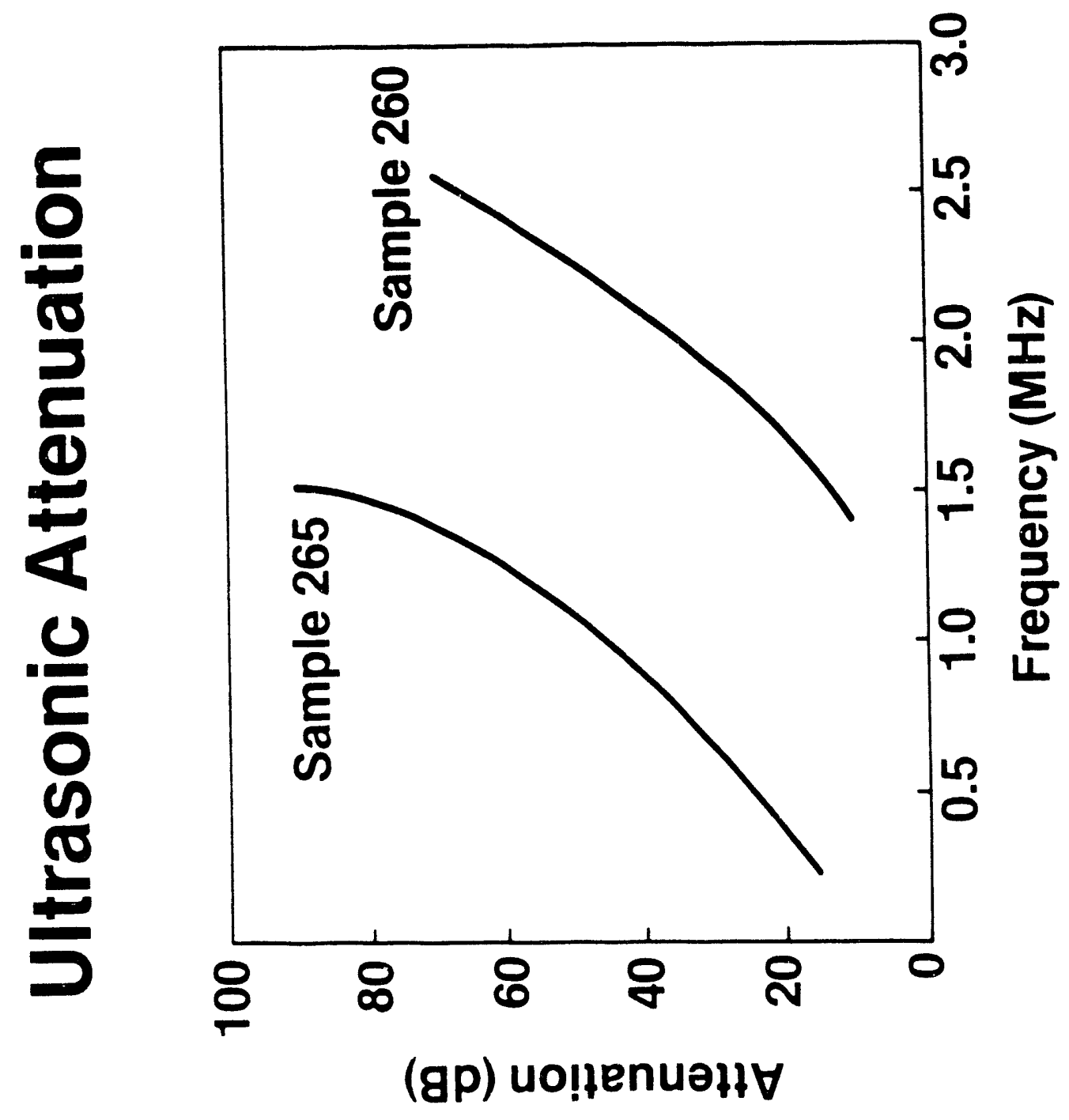

资 
Table 2. Ultrasonic velocities measured using laser-generated ultrasound.

\begin{tabular}{cl} 
Sample & \multicolumn{1}{c}{ Ultrasonic Velocity } \\
\hline Strong Bond (260) & $8.73(\mathrm{~mm} / \mu \mathrm{s})$ \\
Intermediate Bond (NS) & 6.90 \\
Weak Bond (265) & 2.35 \\
\hline
\end{tabular}


Material discontinuities such as porosity and fiber-matrix interfaces primarily affect ultrasonic wave propagation by removing energy from a beam by scattering. This produces beam attenuation and decreases propagation velocity. Scattering also decreases the amplitude of acousto-ultrasonic signals. However, internal absorption of elastic energy is generally not directly caused by porosity and might occur at an imperfectly bonded fiber-matrix interface. This indicates that the AU diffuse field decay rate and the second moment of the AU signal power spectral density can potentially characterize interface bonding. The objective of this part of the study was to determine the AU response to variations in fiber-matrix interface conditions.

\section{Experimental Data}

Acousto-ultrasonic measurements were made on one weak, three intermediate, and one strong interface bond specimens. Following excitation of the pulsing transducer, a $320 \mu \mathrm{s}$ length of the received signal was digitized at a rate of $12.5 \mathrm{MHz}$ and stored. This produced time records of 4,000 points each. The time signals were transformed to the frequency domain with a 4,096 point FFT. Because there can be significant scatter in AU data taken at different points on a single specimen, measurements were taken at 10 positions on each specimen; and the data were processed for each position.

Figure 5 shows typical recorded time signals for the strong bond sample and the weak bond sample. There is an obvious qualitative difference between the two signals. The total energy contained in the signal response from the well-bonded sample is more than 100 times greater than that of the poorly-bonded sample. Based on measurements made on other samples of this material, acoustic property differences of this magnitude would be expected only for material samples having significantly different porosity content. However, since the densities of these samples are approximately the same, the different $A U$ responses are attributed to the differences in fiber-matrix bonding.

Significant differences are also seen in the frequency spectra shown in Figure 20. The spectrum for the weak bond sample shows a marked decrease in high frequency content, indicating a greater absorption of acoustic energy than the stıougly bonded sample. This should correspond to a lower value of $\mathrm{A} 2$ (second moment) and a higher diffuse field decay rate for the weak bond sample.

\section{Diffuse Field Decay Rate Analysis}

Diffuse field decay rate analyses were performed on the AU signals for the interface bond specimens. To process the data, $16 \mu \mathrm{s}$ time windows and $0.5 \mathrm{Mhz}$ frequency bins were used. To avoid initial field transients, the first $48 \mu \mathrm{s}$ of the recorded $\mathrm{AU}$ waveforms were not used. Because there can be a good deal of scatter in AU data taken at different points on a single specimen, measurements were taken at 10 positions on each specimen and the data were processed ior each position. The AU time decay rates for each sample position were then averaged.

The results are shown in Figure 21, in which the averaged time decay rates of each specimen are plotted against trequency. A clear discrimination is observed between different bond strengths; at any given frequency, except at the very low frequency range, the composite specimens exhibit increasing absorption of vibrational energy with decreasing bond strength. The decay rates also increase directly with increasing frequency.

To illustrate the relationship between the $\mathrm{AU}$ results and the material properties, the interfacial shear stress and flexure strength measured by ORNL ${ }^{10}$ for specimens fabricated under identical conditions as the specimens used in this study are plotted in Figure 22 vs. the AU decay rates at $2 \mathrm{MHz}$ frequency. The error bars for interfacial shear stress and flexure strength are those reported by ORNL. ${ }^{10}$ The lines connecting the data points represent least squares fits of the data to second order polynomials and have so other physical significance. The interfacial shear strength measurement technique used by ORNL involves a microhardness indentor to apply a force to the end 


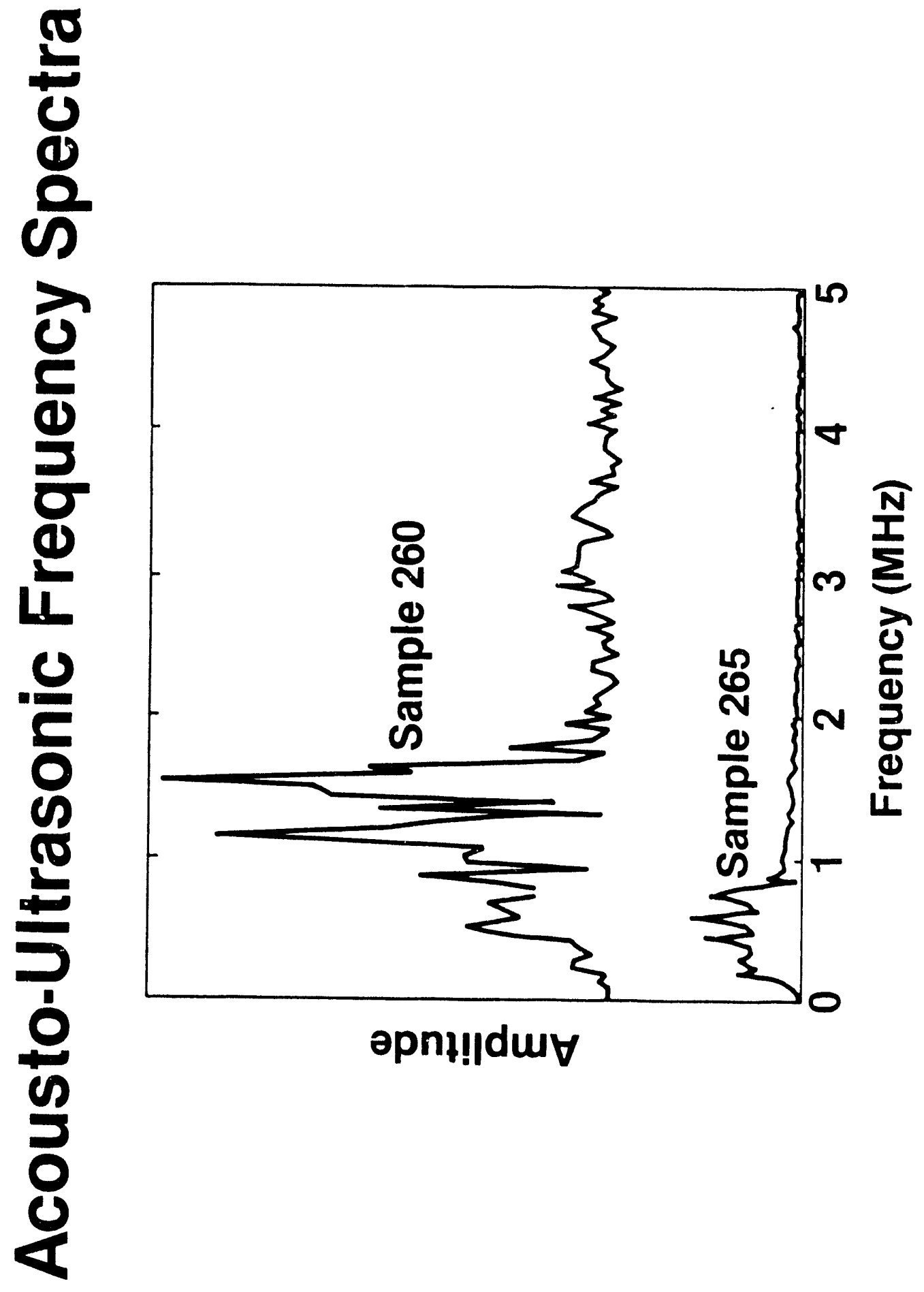

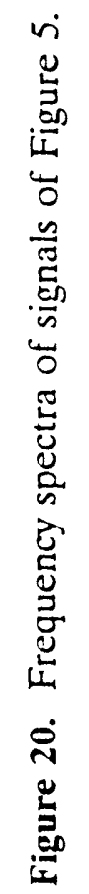




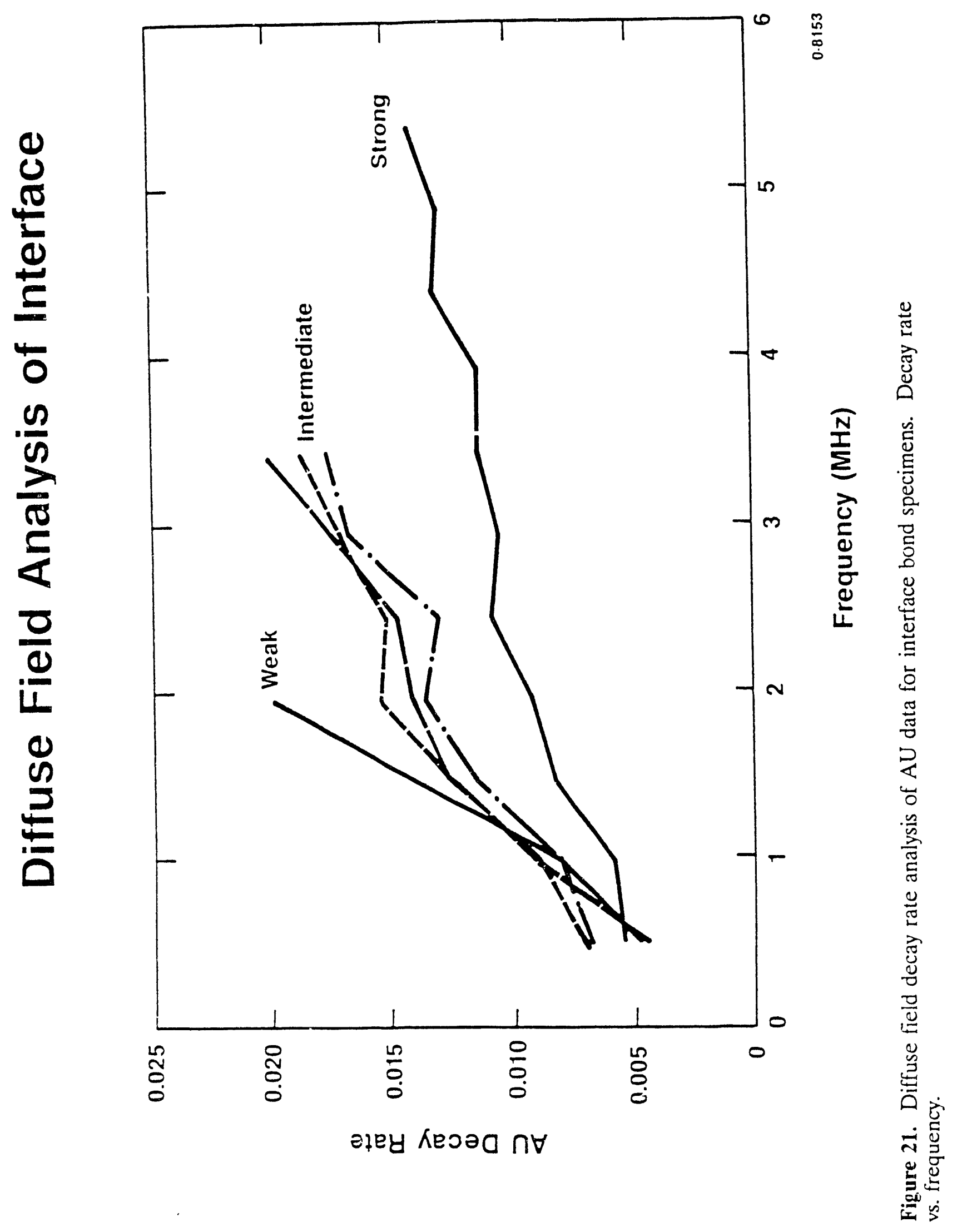


$\frac{\frac{m}{5}}{\frac{m}{2}}$

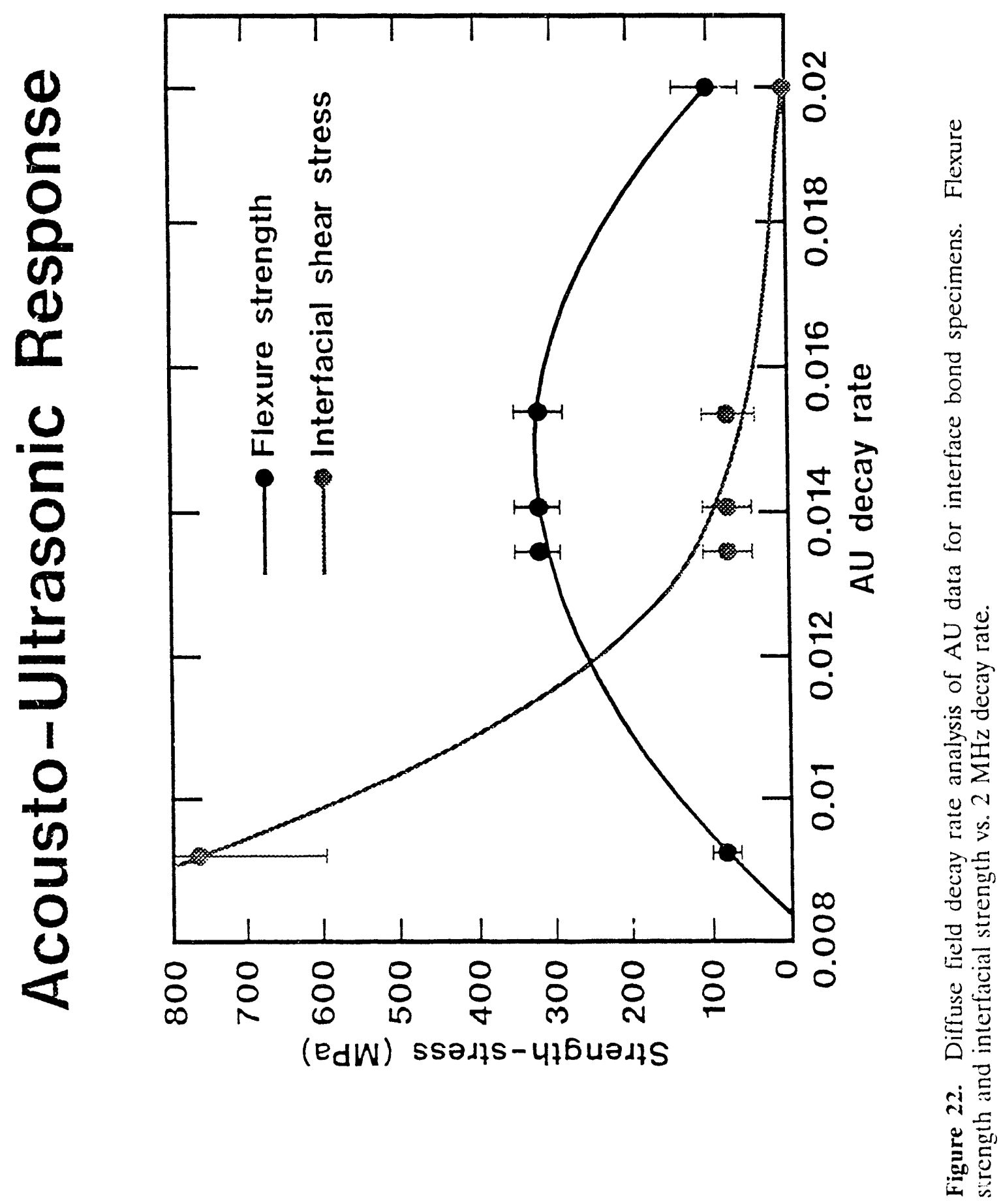


of a fiber imbedded in the matrix. Interfacial shear stresses are determined from the applied load and the observed displacement of the fiber relative to the matrix. Although the interfacial shear stress was not measured on the actual samples for which the AU measurements were made, the figure does show the general relationships involved.

\section{Analysis by Method of Moments}

The AU data were also analyzed by the method of moments. The results are summarized in Figures 23 and 24 . The interfacial shear stress and flexure strength measured by $O R N^{10}$ for specimens fabricated under identical conditions as the specimens used in this study are plotted as functions of $\mathrm{A} 1$ and $\mathrm{A} 2$. The error bars for interfacial shear stress and flexure strength are those reported by ORNL. The lines connecting the data points represent least squares fits of the data to second-order polynomials and have no other physical significance. The differences in the first and second moments of the power spectral density of AU signals are attributed to differences in fibermatrix interface conditions, as the specimens are otherwise identical. This agrees with the results obtained by the diffuse field decay analysis method. 


\section{ACOUSTO-ULTRASONIC RESPONSE SiC/SiC Composite}

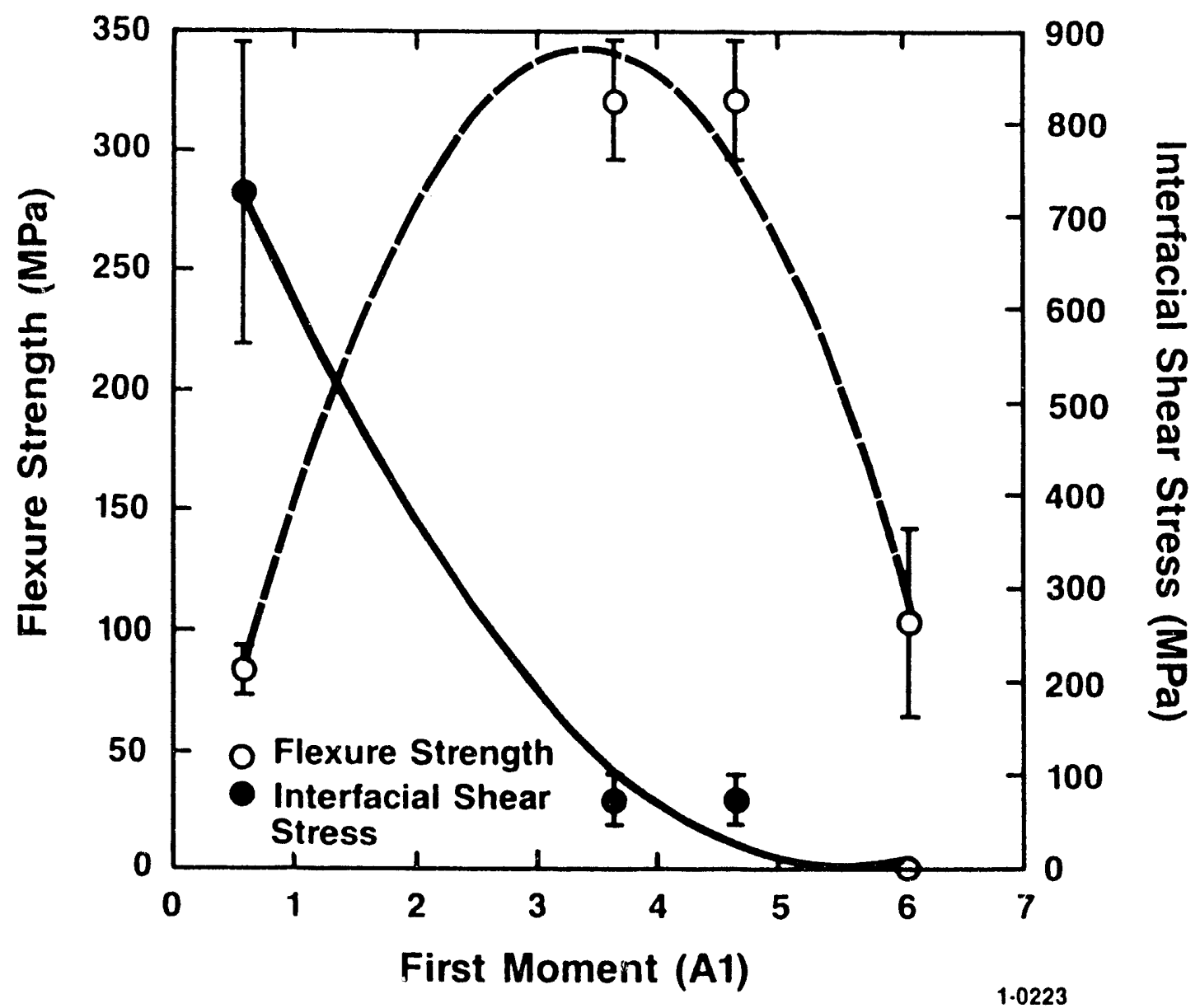

Figure 23. Flexure and interfacial shear stress vs. first moment of AU signal. 


\section{ACOUSTO-ULTRASONIC RESPONSE SiC/SiC Composite}

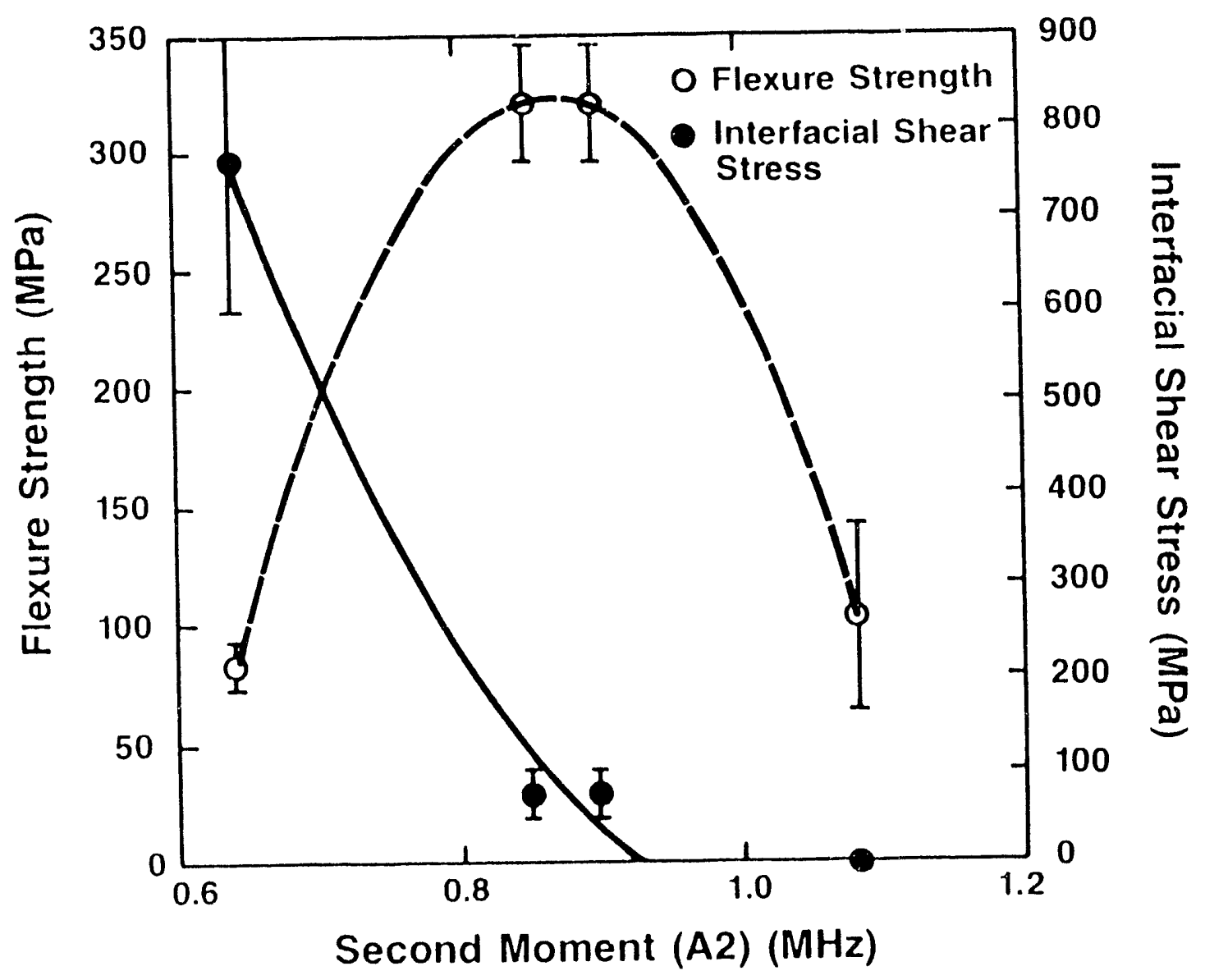

1.6434

Figure 24. Flexure and interfacial shear stress vs. second moment of AU signal. 


\section{SUMMARY AND CONCLUSIONS}

This study has demonstrated the feasibility of acoustic and dynamic mechanical techniques for characterizing performance degrading conditions in ceramic matrix composites. This feasibility includes:

- Measurement of ultrasonic attenuation and porosity for detection and mapping of material porosity

- Ultrasonics and acousto-ultrasonic measurements of internal damping for discriminating between differences in fiber-matrix interface conditions in otherwise identical samples.

- Acousto-ultrasonic measurement of internal mechanical damping for detecting and characterizing mechanical impact damage.

It is important to note that all of the techniques studied are possible with noncontacting laserbased sensors, enabling measurements to be performed on components at high temperatures or in other hostile environments. This means that the techniques have great potential for in situ process monitoring techniques for composite quality control during fabrication and to ensure the quality and integrity of composite materials and components while in service.

Future work should include measurements on larger sample bases to firmly establish correlations between fiber-matrix interface conditions and physical damage states, and measured acoustic and ultrasonic properties. Attention should also be given to effects of component size and shape on measurement and analysis techniques. Finally, additional research needs to be completed on the mechanisms of laser-ultrasonic generation and on detection of ceramic matrix components. 


\section{REFERENCES}

1. R. J. Dewhurst, et al., "Quantitative Measurements of Laser-Generatei' Waveforms," J. Appl. Phys. 53, 4064, 1982.

2. K. L. Telschow, "Microstructure Characterization with a Pulsed Laser Ultrasonic Source," Review of Progress in Quantitative Nondestructive Evaluation, Vol. 7B, Edited by D. O. Thompson and D. E. Chimenti, Plenum Press, 1988, pp. 1211-1218.

3. A. Vary and K. J. Bowles, "An Ultrasonic-Acoustic Technique for Nondestructive Evaluation of Fiber Composite Quality," Polymer Engineering and Science, 19, 1979, pp. 373-377.

4. M. T. Kiernan and J. C. Duke, Jr., "PC Analysis of an Acousto-Ultrasonic Signal," Materials Evaluation, Vol. 46, p. 1344-1352, September 1988.

5. R. L. Weaver, "Diffuse Field Decay Rates For Material Characterization," Solid Mechanics Research for Quantitative Nondestructive Evaluation, edited by J. D. Achenbach and Y. Rajapaskie, Martinus Nijhoff Publishers, 1987, p. 425.

6. L. Lorenzo and H. T. Hahn, "Damage Assessment by Acousto-Ultrasonic Technique in Composites," Composite Materials Testing and Design, STP 972, ASTM, 1988.

7. S. A. Suarez, R. F. Gibson, and L. R. Deobald, "Random and Impulse Techniques for Measurement of Damping in Composite Materials," Experimental Techniques, Vol. 8, No. 10, October 1984, pp. 19-24.

8. R. A. Lowden, D. P. Stinton, and T. M. Besmann, "Characterization of Fiber-Matrix Interfaces in Ceramic Composites," Whisker and Fiber-Toughened Ceramics, ASM Conference Proceedings, 1988, pp. 253-264.

9. A. J. Caputo, D. P. Stinton, R. A. Lowden, and T. M. Besmann, "Fiber-Reinforced SiC Composites with Improved Mechanical Properties," Am. Ceram. Soc. Bull., 66(2), 1987, pp. 368-372.

10. R. A. Lowden, "Characterization and Control of the Fiber-Matrix Interface in Ceramic Matrix Composites," ORNL/TM-11039, March 1989. 

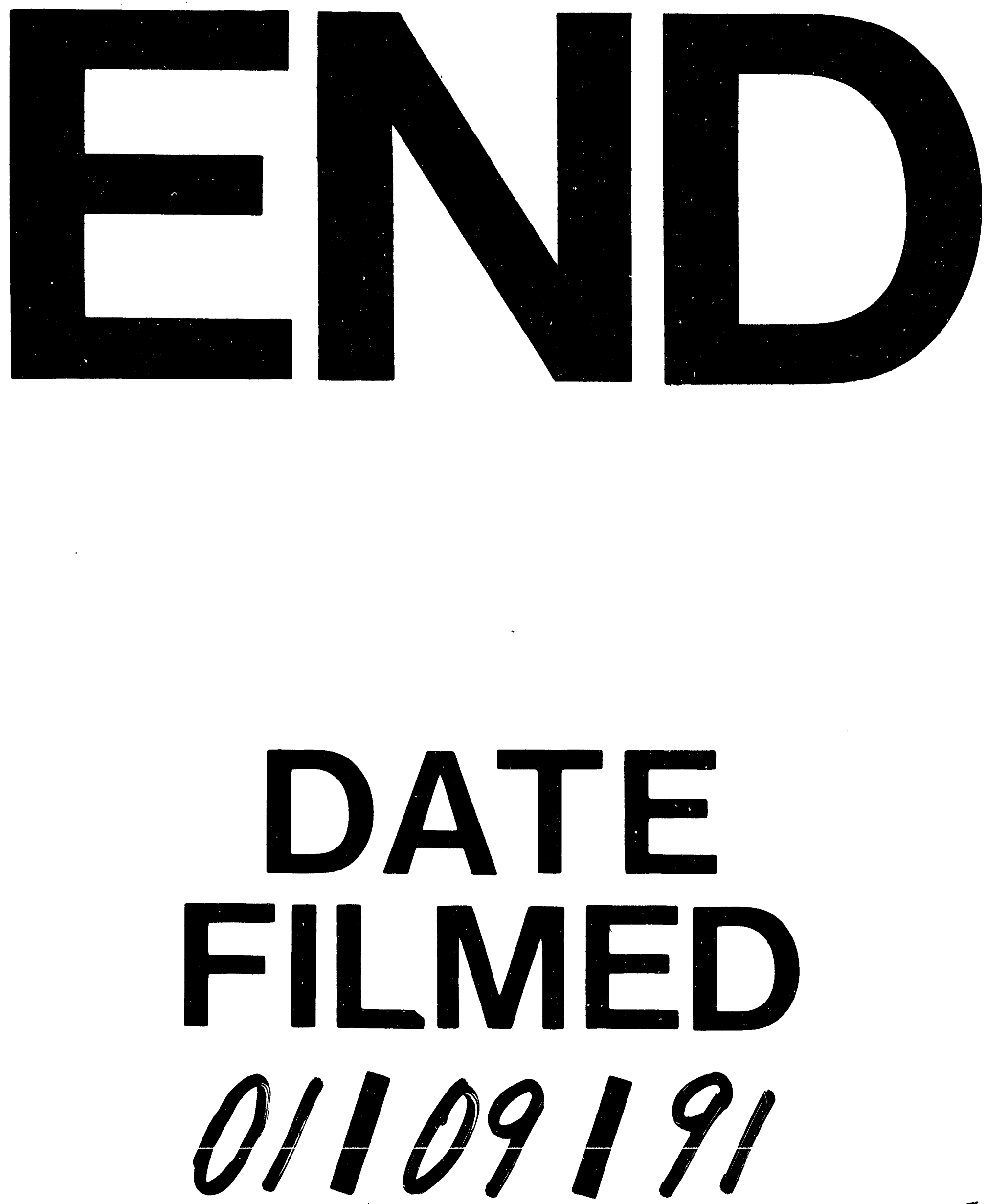

- 
